\title{
TREM2 modulates differential deposition of modified and non-modified $A \beta$ species in extracellular plaques and intraneuronal deposits
}

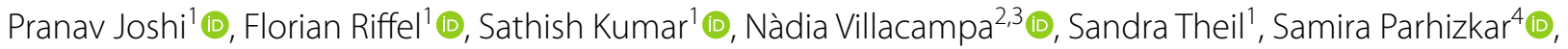 \\ Christian Haass, 4,5, Marco Colonna ${ }^{7}$, Michael T. Heneka ${ }^{2,3}$, Thomas Arzberger ${ }^{6,8,9}$, Jochen Herms ${ }^{5,6,8}$ and \\ Jochen Walter ${ }^{1 *}$ (D)
}

\begin{abstract}
Progressive accumulation of Amyloid- $\beta(A \beta)$ deposits in the brain is a characteristic neuropathological hallmark of Alzheimer's disease (AD). During disease progression, extracellular $A \beta$ plaques undergo specific changes in their composition by the sequential deposition of different modified A $\beta$ species. Microglia are implicated in the restriction of amyloid deposits and play a major role in internalization and degradation of A $\beta$. Recent studies showed that rare variants of the Triggering Receptor Expressed on Myeloid cells 2 (TREM2) are associated with an increased risk for AD. Post-translational modifications of A $\beta$ could modulate the interaction with TREM2, and the uptake by microglia. Here, we demonstrate that genetic deletion of TREM 2 or expression of a disease associated TREM 2 variant in mice lead to differential accumulation of modified and non-modified $A \beta$ species in extracellular plaques and intraneuronal deposits. Human brains with rare TREM2 AD risk variants also showed altered deposition of modified A $\beta$ species in the different brain lesions as compared to cases with the common variant of TREM2. These findings indicate that TREM2 plays a critical role in the development and the composition of $A \beta$ deposits, not only in extracellular plaques, but also intraneuronally, that both could contribute to the pathogenesis of AD.
\end{abstract}

Keywords: TREM2, Microglia, Post-translational modification, A $\beta$, Intraneuronal, Vascular deposits

\section{Background}

Alzheimer's disease (AD) is characterized neuropathologically by the combined occurrence of extracellular amyloid-beta $(\mathrm{A} \beta)$ plaques and intracellular neurofibrillary tangles (NFTs) with abnormally phosphorylated tau $(\tau)$ protein in the brain $[24,65]$. A $\beta$ deposits in the human brain contain different $A \beta$ species, including $\mathrm{N}$-terminal truncated, pyroglutamated, phosphorylated

*Correspondence: jochen.walter@ukbonn.de

${ }^{1}$ Department of Neurology, University of Bonn, Venusberg-Campus 1, (Formerly Sigmund-Freud-Str. 25), 53127 Bonn, Germany

Full list of author information is available at the end of the article and nitrated variants that show significant differences in aggregation, stability, and toxicity $[1,42]$. In particular, $A \beta$ peptides with pyroglutamate-modification at glutamate residue $3(\mathrm{~N} 3 \mathrm{pE}-\mathrm{A} \beta)$ or phosphorylated serine residue 8 (pSer8-A $\beta$ ) have increased propensity to form aggregates with increased neurotoxicity $[38,40-42$, 53]. Previous investigations revealed a specific sequential deposition starting with non-modified $A \beta(n m A \beta)$ peptides, followed by N3pE-A $\beta$ and pSer8-A $\beta$ species in extracellular plaques during the progression from pre-clinical to clinical phases of AD [1,54]. A similar sequence for the deposition of these $A \beta$ species was also found in cerebral amyloid angiopathy (CAA) [11]. 
Genome-wide association studies (GWAS) and exome sequencing have revealed genetic loci related to inflammatory pathways to be associated with an increased risk for $\mathrm{AD}[5,18,71]$. Among these subsets of genes, rare variants of the microglial transmembrane receptor, Triggering Receptor Expressed on Myeloid cells (TREM2), confer a high risk for the development of AD, comparable to the risk exerted by the Apolipoprotein E4 allele (ApoE4) [18, 30]. TREM2 is preferentially expressed in microglia and functions as a receptor for different ligands, including anionic lipids, $A p o E$, and $A \beta[12,47$, $74,82]$. Activation of TREM2 regulates microglial functions, including phagocytosis, cytokine production, proliferation and migration $[16,69,75]$. TREM2 is proteolytically processed by ADAM proteases to generate soluble variants of TREM2 (sTREM2) [25, 34, 78], that can be detected in extracellular fluids. sTREM2 could act as a decoy receptor to negatively modulate TREM2 signaling and inflammatory responses of microglia, and also shows trophic activity to promote microglial survival $[35,83]$.

TREM2 positive microglia cluster around extracellular plaques in brains of human $\mathrm{AD}$ cases and amyloid precursor protein (APP) transgenic mice, and the deletion of TREM2 in APP mouse models results in altered morphology and seeding of plaques, as well as decrease in number of plaque associated microglia $[28,51,67]$, indicating an involvement of TREM2 in the restriction of A $\beta$ deposits $[11,75]$. Here, we sought to characterize the role of TREM2 in accumulation and distribution of modified and non-modified $A \beta$ species in the brain. Deletion of TREM2 or the expression of the disease associated TREM2 ${ }^{\mathrm{T} 66 \mathrm{M}}$ variant in different APP transgenic mouse models led to altered composition not only of extracellular plaques, but also of intraneuronal deposits containing modified and non-modified $A \beta$ variants. Human cases with rare $A D$ associated TREM2 variants also showed altered composition and morphology of the different $A \beta$ pathological lesions as compared to $\mathrm{AD}$ cases with the common TREM2 variant. Together, the data indicate an important role of TREM2 in altering the composition of $\mathrm{A} \beta$ related brain lesions during the pathogenesis of $\mathrm{AD}$.

\section{Methods}

\section{Transgenic mice}

APP695KM670/671NL; PS1L166P TREM2 ${ }^{+/+}$and APP695KM670/671NL; PS1L166P TREM2 $2^{-1-}$ transgenic mice, and 5xFAD $\mathrm{TREM}^{+/+}$and 5xFAD TREM $2^{-/-}$ transgenic mice were described previously $[31,51,66$, $75]$.

$12 \mathrm{M}$ old female APPKM670/671NL; PS1 $\triangle \mathrm{E} 9$ transgenic mice endogenously expressing TREM2 WT or the homozygous TREM2 ${ }^{\mathrm{T} 66 \mathrm{M}}$ knock-in (KI) mutation were obtained from Taconic Biosciences $\mathrm{GmbH}$, Cologne,
Germany [31]. The different mouse models are described in Table 1.

\section{Immunofluorescence (IF) analysis of mouse brains}

Mouse brains were processed as described previously [31, 36, 51]. In brief, $20-25 \mu \mathrm{m}$ sections were sequentially collected in Phosphate-buffered saline (PBS), placed on charged slides, and stained. For IF staining, Reveal Decloaker (Biocare Medical, \#RV1000) was used for antigen retrieval [31] at $95^{\circ} \mathrm{C}$ for $30 \mathrm{~min}$. After this, the sections were washed with PBS and subjected to permeabilization with $0.25 \%$ Triton X-100 for 20 min before blocking for $2 \mathrm{~h}$ in 5\% NHS and 3\% BSA prepared in 1xPBST (Triton X100-0.2\%). Mouse on Mouse Blocking Reagent (Vector laboratories, \#MKB-2213) was used for primary antibodies generated in mouse or rat at a dilution of 1 drop/1000 $\mu$ l. Primary antibodies were diluted in $3 \% \mathrm{NHS}$ and $1.5 \%$ BSA prepared in 1xPBST (Tween 20-0.1\%), added on sections and incubated at $4{ }^{\circ} \mathrm{C}$ overnight. For TREM2 staining, sections were incubated in the primary antibody at $4{ }^{\circ} \mathrm{C}$ for $48 \mathrm{~h}[31,51]$. After washing steps, appropriate secondary antibodies diluted in $3 \%$ NHS and 1.5\% BSA prepared in 1xPBST (Tween $20-0.1 \%$ ) were added on the sections and incubated for $1 \mathrm{~h}$ at RT. The sections were then washed and mounted with VECTASHIELD ${ }^{\circledR}$ Hardset $^{\mathrm{TM}}$ antifade mounting medium (Vector laboratories, \#H-1400) or VECTASHIELD $^{\circledR}$ antifade mounting medium with DAPI (Vector laboratories, \#H-1200). Primary and secondary antibodies are summarized in Additional file 1: Table S1.

\section{Brain protein extraction}

Snap-frozen brain hemispheres were extracted as previously described [22, 70]. Briefly, hemispheres were homogenized in PBS, $1 \mathrm{mM}$ EDTA, $1 \mathrm{mM}$ EGTA, $3 \mu \mathrm{l} /$ $\mathrm{ml}$ protease inhibitor mix (Sigma). Homogenates were extracted in RIPA buffer ( $25 \mathrm{mM}$ Tris- $\mathrm{HCl}$, pH 7.5 , $150 \mathrm{mM} \mathrm{NaCl}, 1 \% \mathrm{NP} 40,0.5 \% \mathrm{NaDOC}, 0.1 \% \mathrm{SDS}$ ), centrifuged at 100,000 $\mathrm{g}$ for $30 \mathrm{~min}$ and the pellet containing insoluble A $\beta$ was solubilized in $2 \%$ SDS, $25 \mathrm{mM}$ Tris$\mathrm{HCl}, \mathrm{pH}$ 7.5. The final protein concentration was determined using PierceTM BCA Protein Assay kit (Thermo Fisher) according to the user's manual.

\section{Immunoblotting}

The brain extracts were separated on $4-12 \%$ NuPAGE gels and transferred to $0.45 \mu \mathrm{m}$ nitrocellulose (NC) membranes as described previously [36]. For immunodetection of proteins, membranes were blocked for $1 \mathrm{~h}$ in $5 \%$ nonfat dry milk in TBST (Tween $20-0.1 \%$ ), then incubated with the primary antibodies in TBST (Tween 20-0.1\%) overnight at $4{ }^{\circ} \mathrm{C}$, followed by three washing steps for 10 min with TBST (Tween $20-0.1 \%$ ), and 


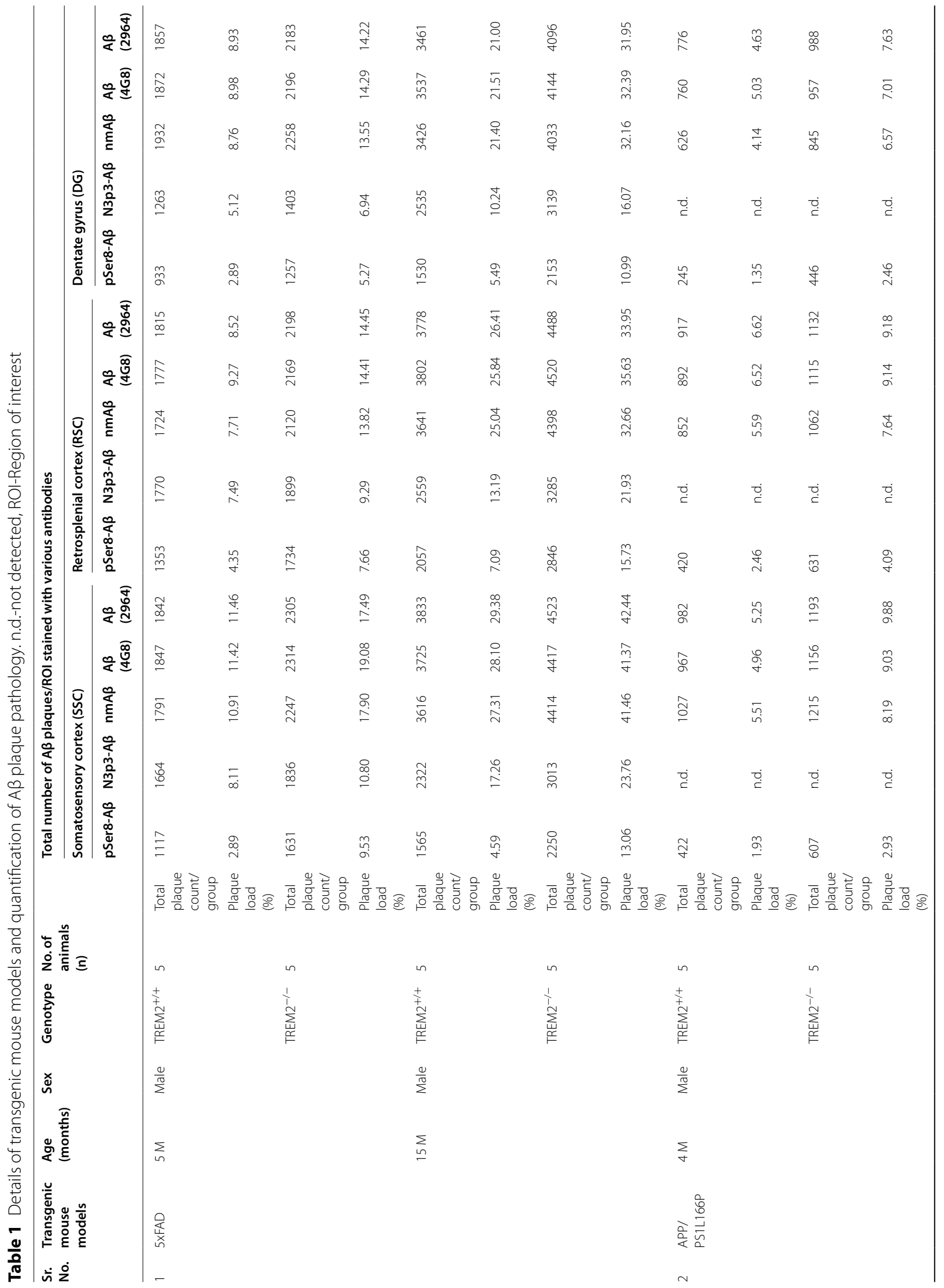




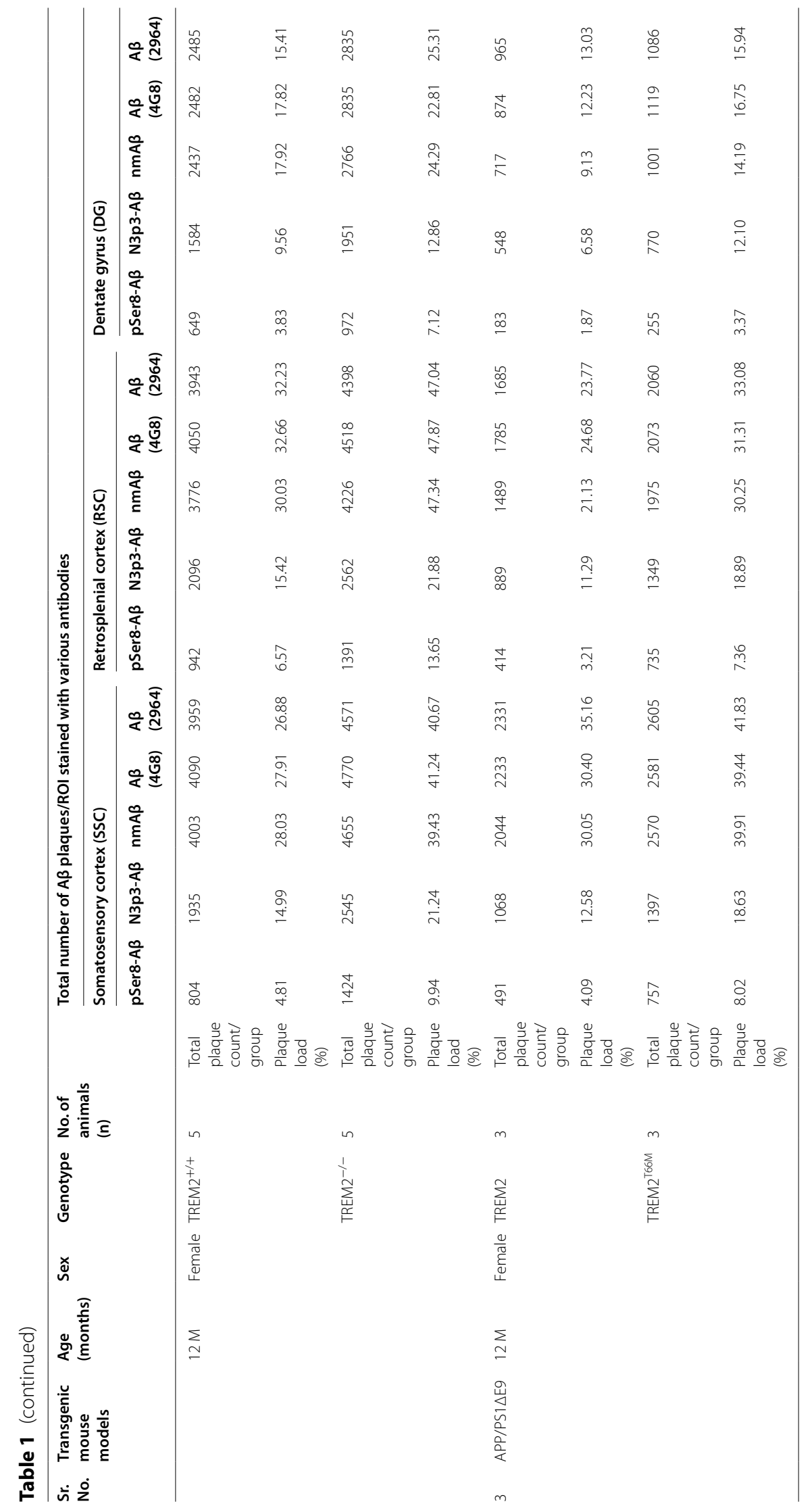


addition of appropriate secondary antibodies in TBST (Tween $20-0.1 \%$ ). After an incubation period of $60 \mathrm{~min}$ at RT, membranes were washed three times for $10 \mathrm{~min}$ with TBST (Tween 20-0.1\%), and once for $5 \mathrm{~min}$ with TBS. For signal detection, the enhanced chemiluminescence ECL imager (Bio-Rad laboratories, Inc.) or Odyssey CLx ${ }^{\mathrm{TM}}$ (LI-COR, Biosciences) were used. The quantification was done by using Image Studio-Lite (Ver. 5.2). Primary and secondary antibodies are summarized in Additional file 1: Table S1.

\section{Patient material}

Tissue samples of patient autopsy cases were provided by the Neurobiobank Munich, Ludwig-Maximilians-University (LMU) Munich. Detailed clinical characteristics were ascertained from an integrated autopsy database. Written informed consent for autopsy and analysis of tissue sample data was obtained for all patients, either from the patients themselves or their kin and the samples were collected according to the guidelines of the local ethics committee following all ethical regulations. Information regarding cases, clinical diagnosis, age at death, postmortem delay, fixation time, AD Braak \& Braak stage, Thal phase, TREM2 coding variant is given in Table 2 . The genotyping and identification of TREM2 variant carriers were done as described before [51]. Sample sizes were based on availability of patient material. For all analyses, temporal neocortex was used which included cortex of medial temporal gyrus at the level of anterior hippocampus.

\section{Immunohistochemistry (IHC) on human post-mortem brain tissue}

IHC was done as described before [51]. In brief, $5 \mu \mathrm{m}$ temporal neocortex sections were mounted on slides, deparaffinized and rehydrated in a series of xylene and graded ethanol. The sections were subjected to citric acid antigen retrieval ( $1 \mathrm{M}$ sodium citrate in $\mathrm{PBS}, \mathrm{pH}$ 6.0) and boiled in a microwave for $20 \mathrm{~min}$. After cooling, endogenous peroxidase activity was quenched using $30 \%$ hydrogen peroxide for $20 \mathrm{~min}$. Sections were blocked and incubated with primary antibodies (Additional file 1: Table S1) overnight at $4{ }^{\circ} \mathrm{C}$. Primary antibodies were detected with biotinylated anti-mouse and anti-rat IgG secondary antibodies and visualized with avidin-biotincomplex (ABC-Kit, Vector laboratories) followed by development with diaminobenzidine- $\mathrm{HCl}$ (DAB, Vector laboratories) for $5 \mathrm{~min}$. Lastly, sections were counterstained with haematoxylin. Stainings were performed in serially cut sections to compare the same region of interest through all immunostainings. Brightfield images were taken with Axio Scan.Z1 (Carl Zeiss MicroImaging $\mathrm{GmbH}$, Germany).

\section{Confocal imaging}

All IF images were acquired using VisiScope CSU-W1 spinning disk confocal microscope and VisiView Software (Visitron Systems GmbH, Germany). Laser and detector settings were maintained constant for the acquisition of each immunostaining. All stainings were repeated at least three times to ensure reproducibility in the staining protocol. Images were acquired at $10 \times$, $20 \times, 40 \times \mathrm{W}$ or $63 \times \mathrm{W}$ (W-water immersion) objective at $2048 \times 2048$ pixels, with $\mathrm{z}$-step size of $1 \mu \mathrm{m}$ (for $10 \times$, $20 \times, 40 \times \mathrm{W}, 63 \times \mathrm{W}$ images) or $4-5 \mu \mathrm{m}$ (for $10 \times$ montage image).

\section{Data analysis of $A \beta$ deposits in mouse and human brain}

Initial optimization of dilutions and incubation times for the different antibodies was carried out for detection of the different $A \beta$ species as reported previously [31, 40, 41]. Sections or areas with folds or poor staining quality were excluded from quantifications. To represent and quantify plaque densities (number and size distribution) from three sections/mouse brains regions, the somatosensory cortex (SSC), the retrosplenial cortex (RSC), and the dentate gyrus (DG) (Additional file 1: Figure S1a), acquired images were imported into Fiji software and data channels were separated (image/color/ split channels). All layers from a single image stack were projected on a single slice (stack/Z-projection) to test the feasibility of quantifying the area and number of plaques (Additional file 1: Figure S1b). The plaques were then segmented and quantified in Fiji using automatic thresholding methods. Due to the thickness of brain sections and the limited penetration of antibody to plaques underneath the sectioned face, lightly embedded stained plaques may or may not be detected depending on image adjustment values (Additional file 1: Figure S1c). Therefore, the plaques and their quantified combined area in this study constitute the "lower boundary" of the plaque number volume density. Furthermore, as demonstrated with digitalized plaques (SSC region stained with $\mathrm{nmA} \beta$ as an example (Additional file 1: Figure S2a-b), the number of plaques assessed using an image analysis method in a given brain region varied depending upon the cut-off value of pixel size and the thresholding of plaques. Initial analysis of optical images revealed that plaque-like images that were digitalized often displayed plaque-like artifacts. Therefore, plaques $>10 \mu \mathrm{m}^{2}$ were considered as reliable "digital plaques". Adjustment of thresholding of certain digitalized plaques appeared to vary in number valuables due to irregularity in plaque shapes or depending upon value of image distribution. It was found that the staining intensity cut-off had a significant impact on the number of plaques. Interestingly, TREM2 knockout 


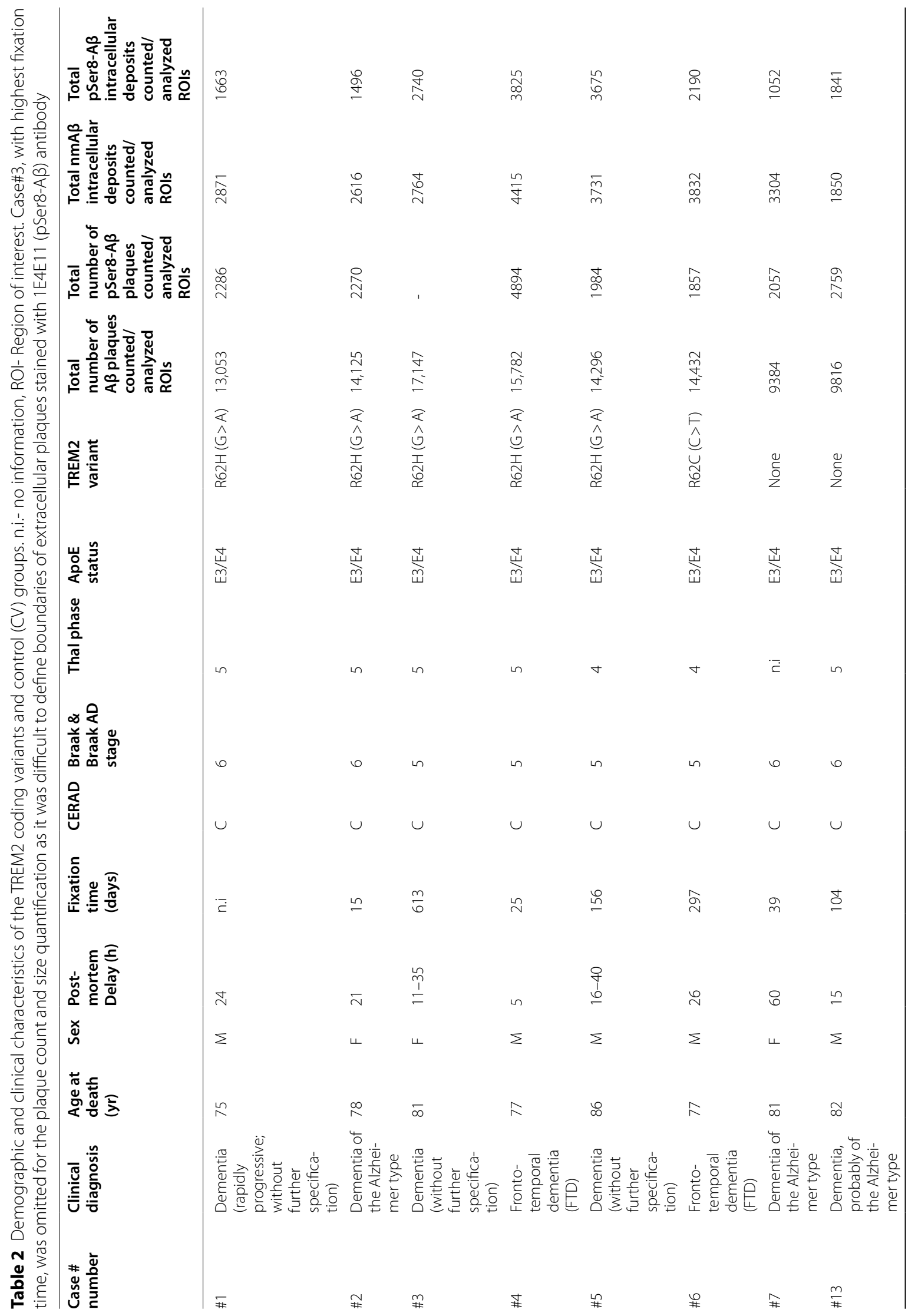




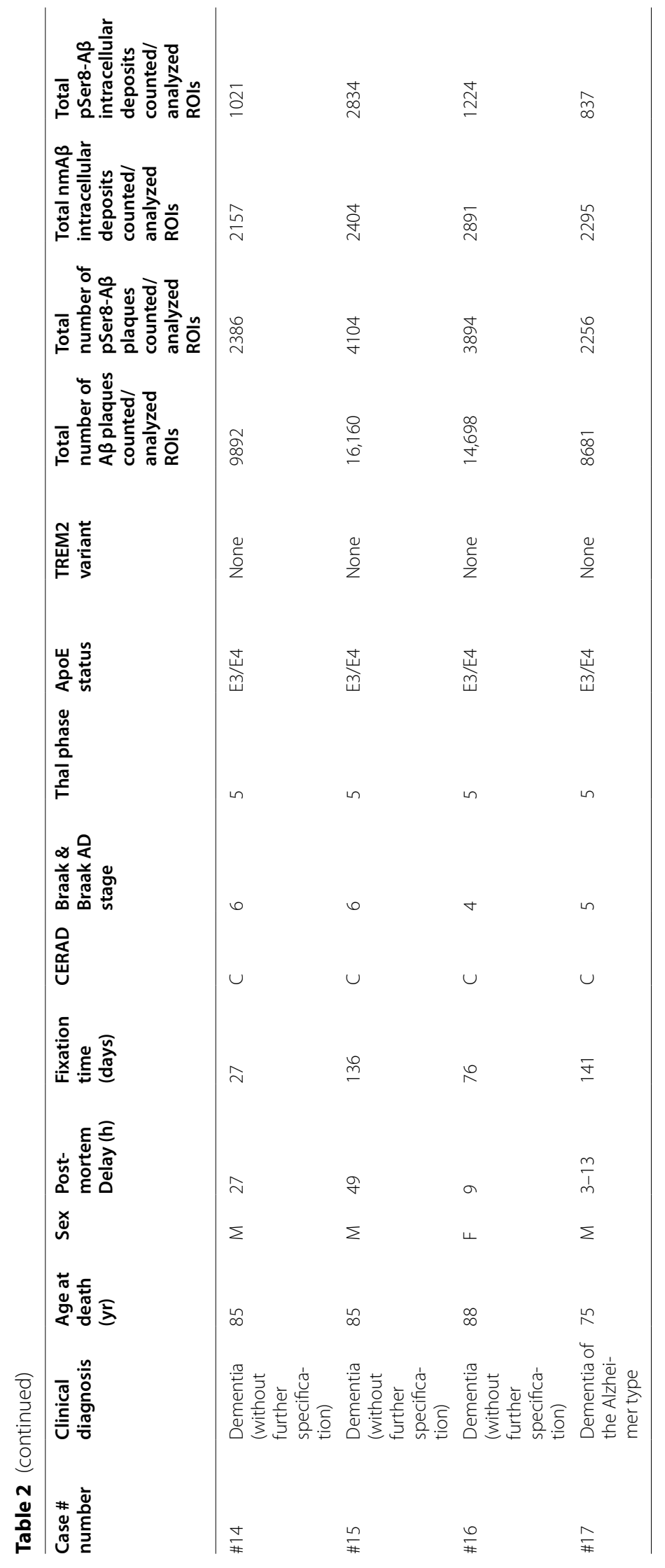


mouse brain, showed large size plaques as well as an increased total number of plaques $>10 \mu \mathrm{m}^{2}$ even at lower thresholding, confirming the validity of the analysis.

For the quantification of plaque ratio in the IF experiments, we considered 300 plaques/region/group (each for SSC and RSC) and 150 plaques/region/group (for DG) (so, $\mathrm{SSC}=60$ plaques/mouse, $\mathrm{RSC}=60$ plaques/ mouse, $\mathrm{DG}=30$ plaques/mouse) so making total of 750 plaques/group containing 5 animals or 450 plaques/ group containing 3 animals (from at least 3 sections/animal). For this analysis, randomly selected plaques that were positive with all three antibodies detecting $A \beta$ species/staining in $1000 \times 1000 \mu \mathrm{m}$ ROI were analyzed by manually drawing boundary around each plaque by using freehand draw tool in Fiji and determining the IntDen [8] of total $A \beta$-immunoreactive area for each plaque stained with various antibodies specific to $A \beta$ species within each section for all channels (Additional file 1: Figure S3).

For quantification of microglia surrounding plaques, microglia surrounding 30 cortical plaques of similar plaque area were manually counted and represented as a mean of 30 plaque associated microglia/animal. The total number of neurons was manually counted in a $1000 \times 1000 \mu \mathrm{m}$ area of SSC, in 2 independently stained sections and represented as a ratio of pSer8- $\mathrm{A} \beta$ positive neurons/total neurons.

For representation and quantification of plaque densities of $4 \mathrm{G} 8$ and $\mathrm{pSer} 8 \mathrm{~A} \beta$ stained plaques in the human brain's sections, 10 cortical $2 \times 2 \mathrm{~mm}$ regions of interest (ROIs) were randomly selected per case and manually quantified. ROIs were selected to allow analysis of the same region for all four consecutive brain sections stained with different antibodies without interference by cuts, folds, or other irregularities (Additional file 2: Source data 1). The total number of plaques along with area measurements were considered for the analysis. The border around plaques was manually drawn by using "spline contour" tool in the ZEN 3.2 software, for the area stained with different antibodies. With 4G8 antibodystained sections, an area cutoff of $10 \mu \mathrm{m}^{2}$ was determined, while with pSer8-A $\beta$ antibody-stained sections, an area cutoff of $30 \mu \mathrm{m}^{2}$ was determined, below which were considered as either artifacts or intracellular deposits (quantified separately). Case\#3, with highest fixation time, was omitted for the plaque count and size quantification as it was difficult to define boundaries of extracellular plaques stained with 1E4E11 (pSer8-A $\beta$ ) antibody. $\mathrm{A} \beta$ plaque load was calculated by summing the areas of all counted plaques divided by the total area of all ROIs. The intracellular deposits of $\mathrm{nmA} \beta$ and phosphorylated $\mathrm{A} \beta$ were manually counted from 10 cortical consecutive $2 \times 2 \mathrm{~mm}$ randomly selected ROIs per case.

\section{Statistical analysis}

Statistical analyses were performed using GraphPad prism software. The plaque area distribution showed positively skewed distribution [58] and varied from the normal distribution confirmed by D'Agostino \& Pearson and the Shapiro-Wilk normality test. Hence, for this analysis, we considered non-parametric, Mann Whitney test (compares the distributions of ranks in two groups) and Kolmogorov-Smirnov test (compares the cumulative distributions) for the frequency distribution of all values. Besides this, since the data were not formally tested, we assumed it followed Gaussian distribution and that the variance between groups was comparable [51]; thus, unless otherwise stated, two-sided, unpaired $t$-test with Welch's correction was used to determine the statistical difference between groups in analyses requiring only single comparisons. The degree of significance between groups is represented as ${ }^{*} p<0.05,{ }^{* * *} p<0.01$, ${ }^{* * * *} p<0.001$, ****** $p<0.0001$, and ${ }^{\mathrm{ns}} p>0.05$.

\section{Randomization and blinding}

The immunohistochemical analysis of mouse and human brains was initially performed blinded with coded slides. However, complete randomization was not possible in the staining with a microglial marker or when stained with anti-TREM2 antibody [31, 51], depicting microglial clustering. No randomization procedure was performed for selecting patient material as case inclusion was largely based on availability. Following the completion of the analysis, the groups were unblinded to perform statistics.

\section{Data collection}

Confocal images were acquired by using VisiScope CSUW1 spinning disk confocal microscope and VisiView Software (Visitron Systems GmbH, Germany). Human brain immunostaining data were acquired by Axio Scan. $\mathrm{Z} 1$ at Plan-Apochromat 20x/0.8M27 objective imaged by Hitachi HV-F202SCL with ZEN 3.2 software (Carl Zeiss MicroImaging GmbH, Germany). FIJI (ImageJ) or ZEN 3.2 software was used for all immunohistochemical analyses. Microsoft Excel was used to organize and to calculate the averages of each repeated experiment. GraphPad (Prism v7.0) software was used to build graphs and perform statistical analyses presented throughout the manuscript.

\section{Validation}

Phosphorylation-state specific antibodies were generated and validated as described previously [38, 41]. Antibody $1 \mathrm{E} 4 \mathrm{E} 11$ is specific for $\mathrm{pSer} 8-\mathrm{A} \beta$ and does not cross-react with other post-translationally modified variants of $A \beta$, including N-terminally truncated $(A \beta 3-42)$, nitrated (3NTyr10-A $\beta)$, pyroglutamated (N3pE-A $\beta)$, or $A \beta$ 
phosphorylated at Ser 26 [41]. Rabbit polyclonal antibody 2964 was raised against aggregated A $\beta$ [73]. TREM2 antibody was verified for immunostainings $[28,51]$. 7H3D6 antibody specifically detects $A \beta$ species with a nonmodified $\mathrm{N}$-terminus and does not recognize phosphorylated Ser8-A $\beta$, but also does not recognize other $A \beta$ variants with $\mathrm{N}$-terminal modifications, including pyroglutamated, nitrated, and N-terminally truncated $A \beta$ species [41]. It is important to note that both antibodies $1 \mathrm{E} 4 \mathrm{E} 11$, detecting $\mathrm{pSer} 8-\mathrm{A} \beta$ and 7H3D6 used for detection of N-terminally non-modified $A \beta$, do not cross-react with full-length APP or APP C-terminal fragments [40, 41]. All the other antibodies used in the study were verified for immunostaining and immunoblotting in mouse and human samples according to the company websites (Additional file 1: Table S1).

\section{Results}

Selective accumulation of Ser8-phosphorylated A $\beta$ species upon loss of TREM2 function in brains of transgenic mice

Phosphorylated $A \beta$ variants were previously detected in brains of transgenic mouse models and human AD cases, and shown to exert increased toxicity in Drosophila models and human neurons derived from embryonic stem or induced pluripotent stem cells [11, 13, 38, 40, 41, 54]. To assess the role of TREM2 in the deposition of modified A $\beta$ species in-vivo, $5 x F A D$ transgenic mice were crossed with TREM $2^{+/+}$or TREM $2^{-/-}$mice as described previously $[31,51]$ (Table 1), and the deposition of different A $\beta$ species was analyzed using several antibodies selectively detecting modified and non-modified variants of $\mathrm{A} \beta$. Monoclonal antibody $1 \mathrm{E} 4 \mathrm{E} 11$ specifically detects pSer8-A $\beta$ species, while monoclonal antibody 7H3D6 selectively recognizes $A \beta$ with Ser8 in non-phosphorylated state. Antibody 7H3D6 also does not recognize other $\mathrm{A} \beta$ variants with $\mathrm{N}$-terminal modifications, including pyroglutaminated, nitrated, and N-terminally truncated $\mathrm{A} \beta$ species [41].

Triple staining with mouse monoclonal 1E4E11, rat monoclonal 7H3D6, and rabbit polyclonal 2964 antibodies revealed that TREM $2^{-1-}$ mice at 15 months $(15 \mathrm{M})$ of age had significantly more plaques detected by all three antibodies. Elevated plaque deposition, as measured by the plaque number (Fig. 1a-b, Additional file 1: Figure S4) and plaque load (Table 1), was detected in the three different brain regions analyzed, the somatosensory cortex (SSC), the retrosplenial cortex (RSC), and the dentate gyrus (DG). Consistent with a preferential deposition in the core of plaques, $\mathrm{pSer} 8-\mathrm{A} \beta$ positive deposits are of smaller size than those containing $\mathrm{nmA} \beta$ that is also deposited in the corona of plaques (Fig. 1c, Additional file 2: Source data 2a-c). These findings are consistent with the function of TREM2 to restrict plaque size or growth $[75,81]$, and also demonstrate the importance of TREM2 to limit accumulation of pSer8-A $\beta$ in the core of plaques. A selective increase in pSer8-A $\beta$ was detected by analyzing the mean fluorescence signal intensities within $A \beta$ deposits (Fig. 1d-e). Furthermore, increased number and size of $\mathrm{pSer} 8-\mathrm{A} \beta$ and $\mathrm{nmA} \beta$ positive plaques in $5 \mathrm{xFAD}$ TREM $2^{-1-}$ compared to TREM2 $2^{+/+}$mouse brains was already observed in $5 \mathrm{M}$ old mice (Fig. $2 \mathrm{a}-\mathrm{b}$, Additional file 2: Source data 2d-f). Analysis of plaque size distribution at both ages revealed overall increased numbers of deposits of various sizes in all three analyzed brain regions of TREM2 $2^{-1-}$ mice (Additional file 2: Source data 2). In particular, the number of deposits $>1200 \mu \mathrm{m}^{2}$ that are also positive for pSer8-A $\beta$ were strongly increased in TREM $2^{-/-}$mice already at $5 \mathrm{M}$ of age, suggesting that TREM2 decreases the formation and growth of plaques already at early stages of deposition. However, the ratio of the mean fluorescence intensity for pSer8-A $\beta$ and $\mathrm{nmA} \beta$ was similar in TREM $2^{-1-}$ and TREM2 $2^{+/+}$at this young age (Fig. $2 \mathrm{c}-\mathrm{d}$ ), indicating that TREM2 deficiency promotes co-deposition of different A $\beta$ species. Very similar findings were obtained with an independent double-transgenic APP/PS1L166P mouse model (Table 1, Additional file 1: Figure S5, Additional file 2: Source data 3).

Pyroglutamate-modified $\mathrm{A} \beta(\mathrm{N} 3 \mathrm{pE}-\mathrm{A} \beta)$ also accumulates during the pathogenesis of $\mathrm{AD}$ in the cortex and hippocampus [52, 55]. Immunohistochemical analyses showed that TREM2 ${ }^{-1-}$ mice had significantly more $\mathrm{N} 3 \mathrm{pE}-\mathrm{A} \beta$ positive plaques at $15 \mathrm{M}$ of age in the SSC, RSC, and the DG as compared to TREM2 ${ }^{+/+}$mice. Consistent

\footnotetext{
(See figure on next page.)

Fig. 1 TREM2 deletion leads to increased deposition of pSer8-A $\beta$ in $15 \mathrm{M}$ old $5 \times F A D$ transgenic mouse brains. a Representative pSer8-A $\beta$ stained male $15 \mathrm{M}$ old-5xFAD-TREM2 ${ }^{+/+}$and TREM2 ${ }^{-/-}$mouse brain sections (color scale bar $=35 \mathrm{~mm}$, represents $\mathrm{min} / \mathrm{max}$ pixel intensities, $10 \mathrm{x}$ ). $\mathbf{b}$ Dot plots representing number of plaques $/ \mathrm{mm}^{2}, \mathbf{c}$ Box and whiskers plots showing plaque size $\left(\mu \mathrm{m}^{2}\right)$ stained with $p S e r 8-A \beta, n m A \beta$ and $A \beta$ (2964) antibodies in the SSC, RSC, and DG of male 15 M-5xFAD-TREM2 ${ }^{-/-}$and TREM2 $2^{+/+}$mice. $\mathbf{d}$ Representative images showing deposition of pSer8-A $\beta, n m A \beta$, and A $(2964)$ in SSC of male $15 \mathrm{M}-5 \times$ FAD-TREM2 ${ }^{-/-}$and TREM2 $2^{+/+}$mice (scale bar $=50 \mu \mathrm{m}, 40 \times \mathrm{W}$ ). e Ratios of $\mathrm{pSer} 8 / \mathrm{nmA} \beta$ in SSC $\left(t(7.41)=7.856,{ }^{* * * *} p<0.0001\right)$, RSC $\left(t(7.696)=7.611,{ }^{* * *} p<0.0001\right)$, and DG $\left(t(7.945)=6.345,{ }^{* * *} p=0.0002\right)$ of male 15 M-5xFAD-TREM2 ${ }^{-/-}$ compared with TREM2 ${ }^{+/+}$mice. Each dot represents average value of the number of plaques or the ratio of pSer8-A $\beta / \mathrm{nmA} \beta$ per animal. The box and whiskers plots represent $\mathrm{min} / \mathrm{max}$ values of distribution of plaque size with the median (shown by the line dividing the box) and the dot plots represent mean \pm SEM $\left(n=5\right.$ animals, color- blue $\left(5 x\right.$ FAD-TREM $\left.2^{+/+}\right)$and green (5xFAD-TREM2 $\left.{ }^{-/-}\right)$, unpaired t-test with Welch's correction for analysis of the number and ratio while Mann-Whitney test for plaque size, ${ }^{n s} p>0.05,{ }^{*} p<0.05,{ }^{* *} p<0.01,{ }^{* * *} p<0.001$ or ${ }^{* * * *} p<0.0001$ )
} 


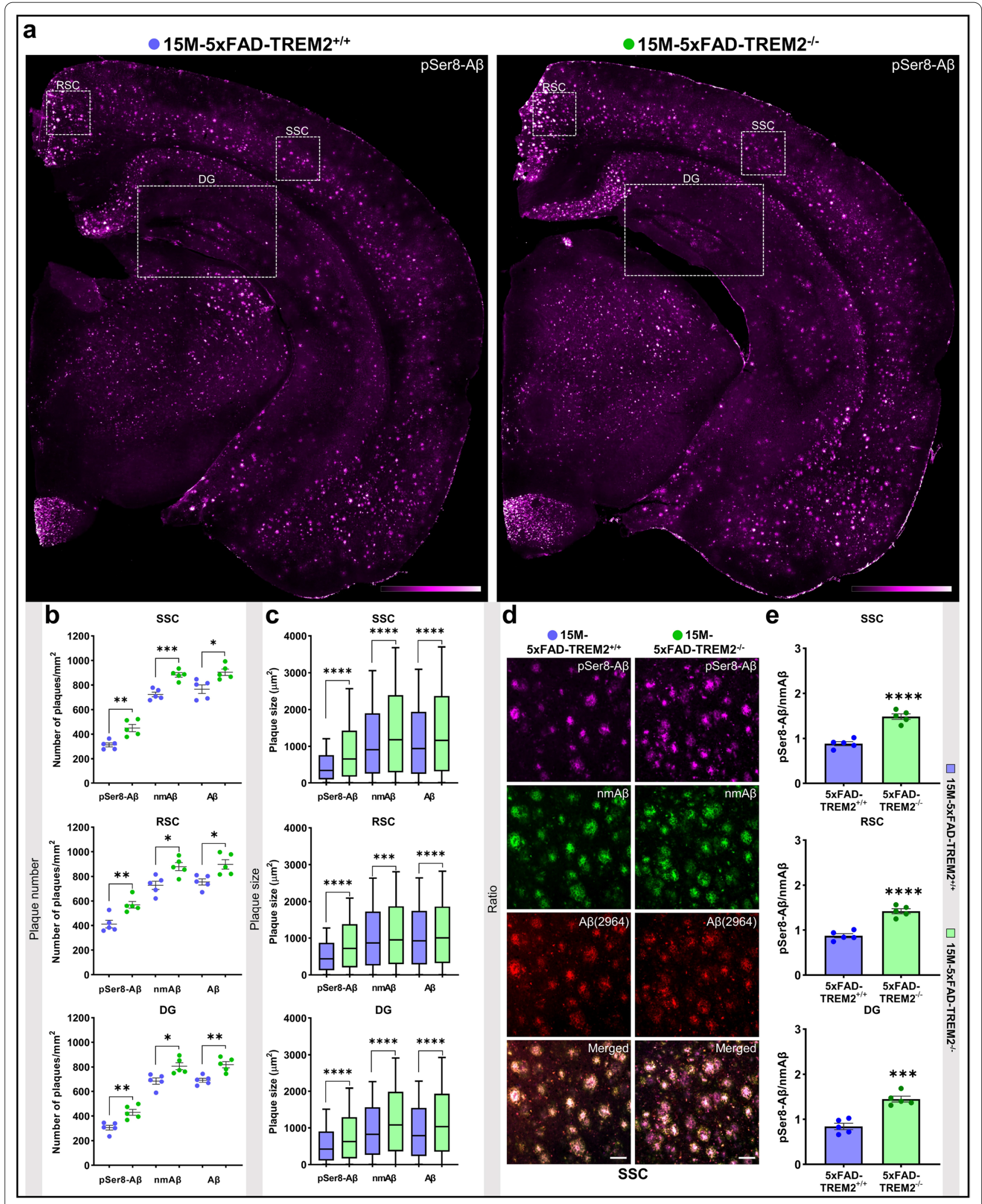

Fig. 1 (See legend on previous page.) 


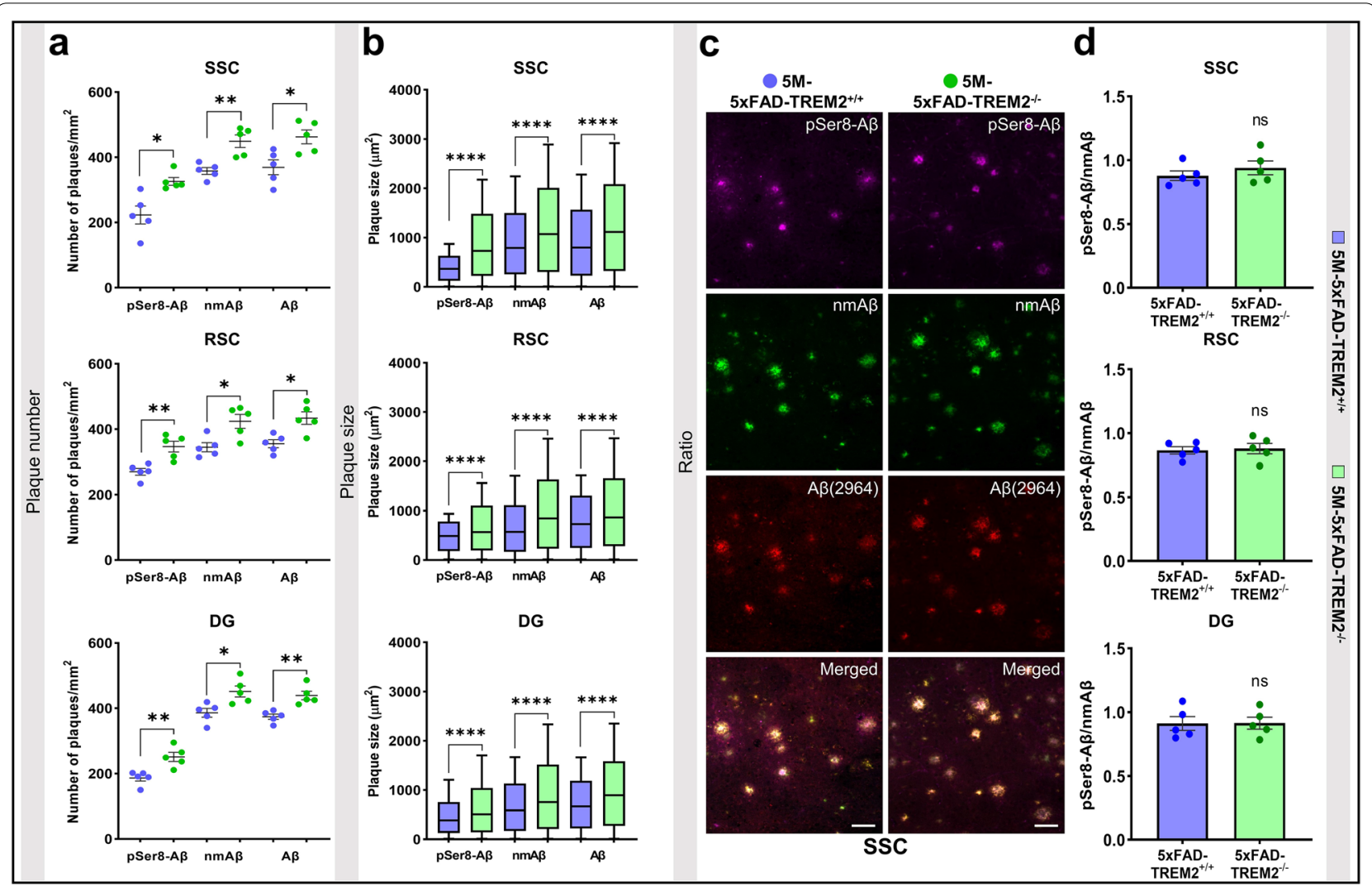

Fig. 2 TREM2 deletion leads to increased deposition of pSer8-A 3 in $5 \mathrm{M}$ old $5 x F A D$ transgenic mouse brains. a Dot plots representing number of plaques $/ \mathrm{mm}^{2}$, b Box and whiskers plots showing plaque size $\left(\mu \mathrm{m}^{2}\right)$ stained with pSer8-A $\beta, n m A \beta$ and A $\beta$ (2964) antibodies in the SSC, RSC, and DG of male $5 \mathrm{M}$ old-5xFAD-TREM2 ${ }^{-/-}$and TREM2 ${ }^{+/+}$mice. $\mathbf{c}$ Representative images showing deposition of pSer8-A $\beta$, nmA $\beta$, and A $\beta$ (2964) in SSC of male 5 M-5x-FAD-TREM2 $2^{-/-}$and TREM2 $2^{+/+}$mice (scale bar $=50 \mu \mathrm{m}, 40 \times \mathrm{W}$ ). $\mathbf{d}$ Ratio of pSer8/nmA 3 in SSC, RSC and DG in male $5 \mathrm{M}-5 \times \mathrm{XAD}-\mathrm{TREM}_{2}{ }^{-/}$compared to TREM2 ${ }^{+/+}$mice. Each dot represents average value of the number of plaques or the ratio of $\mathrm{pSer} 8-\mathrm{A} \beta / \mathrm{nmA} \beta \mathrm{per}$ animal. The box and whiskers plots represent $\mathrm{min} / \mathrm{max}$ values of distribution of plaque size with the median (shown by the line dividing the box) and the dot plots represent mean \pm SEM $\left(n=5\right.$ animals, color- blue $\left(5 x F A D-T R E M 2^{+/+}\right)$and green $\left(5 \times F A D-T R E M 2^{-/-}\right)$, unpaired t-test with Welch's correction for analysis of the number and ratio while Mann-Whitney test for plaque size, ${ }^{\text {ns }} p>0.05,{ }^{*} p<0.05,{ }^{* *} p<0.01$ or ${ }^{* * * *} p<0.0001$ )

with data shown in Fig. 1, TREM2-l- mice showed higher number of plaques, (Fig. 3a-b), increased size of plaques (Fig. 3c, Additional file 2: Source data 2a-c) and elevated plaque load (Table 1) in all three regions as revealed by co-staining with antibodies detecting $\mathrm{N}$-terminally non-modified $A \beta$ and total $A \beta$ species at $15 \mathrm{M}$ of age. In contrast to pSer8-A $\beta, N 3 p E-A \beta$ was not selectively increased in plaques as compared to $\mathrm{nmA} \beta$ at $15 \mathrm{M}$ of age, as evidenced by similar ratios of $\mathrm{N} 3 \mathrm{pE}-\mathrm{A} \beta / \mathrm{nmA} \beta$ in all analyzed brain regions (Fig. 3d). At $5 \mathrm{M}$ of age, the total number of N3pE-A $\beta$ deposits were only slightly, but not significantly increased in 5xFAD TREM $2^{-1-}$ mice as compared to TREM2 $2^{+/+} 5 x$ FAD mice (Fig. 3e-f). However, as observed with $15 \mathrm{M}$ old mice, there was a significant increase in the size of $\mathrm{N} 3 \mathrm{pE}-\mathrm{A} \beta$ positive plaques especially for larger deposits $>1500 \mu \mathrm{m}^{2}$ already at $5 \mathrm{M}$ in $5 \mathrm{xFAD}$ TREM2 $^{-1-}$ mice (Fig. 3g, Additional file 2: Source data
$2 d-f)$. Analysis of plaque size distribution revealed that there was an increase in the number of N3pE-A $\beta$ deposits at both age groups, again particularly pronounced for deposits $>1500 \mu \mathrm{m}^{2}$. An increase of pSer8-A $\beta$ and $\mathrm{N} 3 \mathrm{pE}-\mathrm{A} \beta$ deposits $<600 \mu \mathrm{m}^{2}$ in the three analyzed brain regions of TREM $2^{-/-}$mice as compared to TREM2 ${ }^{+/+}$ mice was only observed at $15 \mathrm{M}$ of age (Additional file 2: Source data 2 ). The N3pE-A $\beta / \mathrm{nmA} \beta$ intensity ratio in the analyzed brain regions was not different between TREM $2^{-/-}$and TREM $2^{+/+}$mice at both ages (Fig. $3 \mathrm{~d}, \mathrm{~h}$ ). Very similar findings were obtained with the independent double-transgenic APP/PS1L166P mouse model (Additional file 1: Figure S6, Additional file 2: Source data 3). These findings indicate that N3pE-A $\beta$ species showed increased deposition upon deletion of TREM2. However, $\mathrm{N} 3 \mathrm{pE}-\mathrm{A} \beta$, in contrast to pSer8-A $\beta$, did not selectively accumulate upon deletion of TREM2 in relation to $\mathrm{nmA} \beta$. 


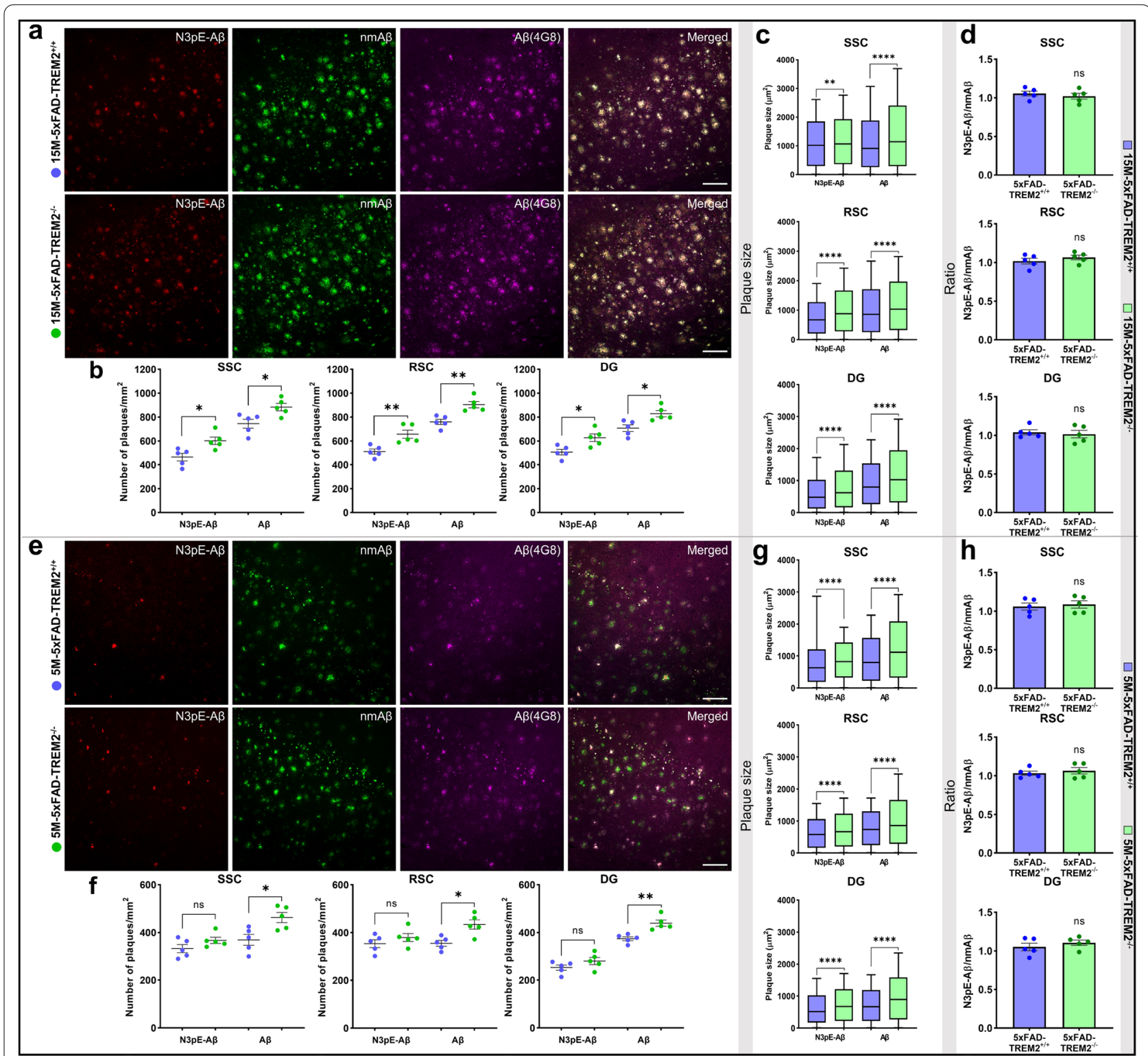

Fig. 3 TREM2 deletion leads to increased N3pE-A deposits in 5 XFAD transgenic mouse brains. a Representative images showing deposition of N3pE-A $\beta, n m A \beta$, and A $\left(4 \mathrm{G} 8\right.$ ) in SSC of male $15 \mathrm{M}$ old-5xFAD-TREM2 ${ }^{-/-}$and TREM2 ${ }^{+/+}$mice (scale bar $=200 \mu \mathrm{m}, 20 \mathrm{x}$ ). b Dot plots representing number of plaques $/ \mathrm{mm}^{2}, \mathbf{c}$ Box and whiskers plots showing plaque size $\left(\mu \mathrm{m}^{2}\right)$ stained with N3pE-A 3 and $A \beta(4 \mathrm{G} 8)$ antibodies in the SSC, RSC, and DG of the male 15 M-5xFAD-TREM2 ${ }^{-/}$and TREM2 ${ }^{+/+}$mice. $\mathbf{d}$ Ratio of N3pE-A $/ \mathrm{nm} A \beta$ in the SSC, RSC, and DG of male 15 M-5XFAD-TREM2 ${ }^{-/-}$compared with TREM2 ${ }^{+/+}$mice. e Representative images showing deposition of N3pE-A $3, n m A \beta$, and A $(4 \mathrm{G} 8$ ) in SSC of male $5 \mathrm{M}-5 \times$ XAD-TREM2 ${ }^{-/-}$and TREM2 $2^{+/+}$mice (scale bar $\left.=200 \mu \mathrm{m}, 20 \mathrm{x}\right)$. $\mathbf{f}$ Dot plots representing number of plaques $/ \mathrm{mm}^{2}, \mathbf{g}$ Box and whiskers plots showing plaque size $\left(\mu \mathrm{m}^{2}\right)$ stained with N3pE-A 3 and A $\left(4 \mathrm{G} 8\right.$ ) antibodies in the SSC, RSC, and DG of male 5 M-5xFAD-TREM2 ${ }^{-/-}$and TREM $2^{+/+}$mice. $\mathbf{h}$ Ratio of N3PE-A $\beta / \mathrm{nmA} \beta$ in the SSC, RSC, and DG of male $5 \mathrm{M}-5 \mathrm{xFAD}-\mathrm{TREM} 2^{-/-}$compared with TREM2 ${ }^{+/+}$mice. Each dot represents average value of the number of plaques or the ratio of $\mathrm{N} 3 \mathrm{pE}-\mathrm{A} \beta / \mathrm{nmA} \beta$ per animal. The box and whiskers plots represent $\mathrm{min} / \mathrm{max}$ values of distribution of plaque size with the median (shown by the line dividing the box) and the dot plots represent mean $\pm S E M(n=5$ animals, color- blue $\left(5 \times\right.$ XAD-TREM $2^{+/+}$) and green (5xFAD-TREM2 $2^{+/+}$), unpaired t-test with Welch's correction for analysis of the number and ratio while Mann-Whitney test for plaque size, ${ }^{\text {ns }} p>0.05,{ }^{*} p<0.05,{ }^{* *} p<0.01$ or ${ }^{* * * *} p<0.0001$ ) 


\section{TREM2 ${ }^{\mathrm{T} 66 \mathrm{M}}$ mutation leads to increased deposition of $\mathrm{pSer} 8-\mathrm{A} \beta$ in transgenic mouse brain}

To assess potential effects of a disease associated TREM2 mutant, we used knock-in (KI) mice that carry the TREM2 $2^{\mathrm{T} 66 \mathrm{M}}$ variant (Table 1 ). The TREM2 ${ }^{\mathrm{T} 66 \mathrm{M}}$ variant is associated with Nasu-Hakola disease (NHD) and frontal lobe degeneration $[17,19,49]$. Importantly, the genetic modification at this site in the mouse genome does not result in aberrant splicing and lower mRNA levels as observed previously for knock-in mice expressing the Alzheimer-associated $\mathrm{R} 47 \mathrm{H}$ variant [79]. TREM2 ${ }^{\mathrm{T} 66 \mathrm{M}} \mathrm{KI}$ mice were crossed with APP/PS1 $\Delta \mathrm{E} 9$ double transgenic mice. Mice homozygous for endogenous TREM2 or the TREM2 ${ }^{\mathrm{T} 66 \mathrm{M}} \mathrm{KI}$ mutation were analyzed at $12 \mathrm{M}$ of age. Homozygous TREM2 ${ }^{\mathrm{T} 66 \mathrm{M}}$ KI mice showed an increase in the number and size of plaques (Fig. 4a-c, Additional file 2: Source data 4) as well as increased plaque load (Table 1). TREM2 ${ }^{\mathrm{T} 66 \mathrm{M}} \mathrm{KI}$ mice also showed a selective accumulation of pSer8-A $\beta$ in plaques as compared to $n m A \beta$ (Fig. 4d-e). Moreover, there was an increase in the number of larger sized $\left(>1500 \mu \mathrm{m}^{2}\right)$ as well as smaller sized $\left(<600 \mu \mathrm{m}^{2}\right)$ deposits of N3pE-A $\beta$ along with pSer8-A $\beta, n m A \beta$ and total $A \beta$ species in the analyzedbrain regions of TREM2 $2^{\mathrm{T} 66 \mathrm{M}}$ mice (Fig. $4 \mathrm{f}-\mathrm{h}$, Additional file 2: Source data 4). Again, no selective accumulation of $\mathrm{N} 3 \mathrm{pE}-\mathrm{A} \beta$ as compared to that of $\mathrm{nmA} \beta$ was observed in brains of TREM2 $2^{\text {T66M }}$ expressing mice (Fig. $4 \mathrm{i}-\mathrm{j}$ ). These findings further support a selective increase of pSer8-A $\beta$ in parenchymal plaques in mice with impaired TREM2 function.

\section{Loss of TREM2 function increases intraneuronal and vascular deposition of $A \beta$ species}

Clustering of Iba1 positive microglia around plaques was apparent in the different APP transgenic mouse models expressing endogenous TREM2 at advanced and earlier stages of $A \beta$ deposition, but was strongly reduced in brains of the respective TREM $2^{-/-}$(Additional file 1: Figure S7a-b) and TREM2 ${ }^{\mathrm{T} 66 \mathrm{M}} \mathrm{KI}$ mice (Fig. 5a-b). Consistent with previous reports $[8,28,51]$, TREM $2^{-1-}$ mice showed much less compact $A \beta$ deposits as compared to TREM2 $2^{+/+}$mice. Similar observations were made with the APP/PS1 $\triangle E$ E-TREM2 ${ }^{\mathrm{T} 66 \mathrm{M}} \mathrm{KI}$ mice as compared to APP/PS1 $\triangle E$ 9-TREM2 mice, indicating that impaired barrier function of microglia caused by dysfunctional TREM2 promotes the deposition of smaller plaques containing pSer8-A $\beta$. In addition, brains of APP transgenic TREM2 $2^{-1-}$ and TREM2 $2^{\text {T66M }}$ KI mice showed strongly elevated deposition of $\mathrm{pSer} 8-\mathrm{A} \beta$ within neurons as compared to brains from APP transgenic mice expressing endogenous functional TREM2 (Fig. $5 c-d$, Additional file 1: Figure S7c-d).
We also performed western immunoblotting analyses with different fractions of brain extracts from APP/ PS1 $\triangle$ E9-TREM2 and APP/PS1 $\triangle$ E9-TREM2 ${ }^{\text {T66M }}$ KI mice. Levels of pSer8-A $\beta, n m A \beta$, and total $A \beta$ (immunostained with 4 G8 or 2964 antibody) were significantly increased in the RIPA extracts with low detergent concentration that could contain extracellular and membrane-associated monomeric and oligomeric $\mathrm{A} \beta$ species (Fig. $6 \mathrm{a}-\mathrm{h}$ ). Consistent with the higher aggregation propensity of pSer8-A $\beta$, pSer8-A $\beta$ reactivity was also observed in the upper region of the blot that likely represent SDS-stable oligomers. These species were also detected by antibodies $4 \mathrm{G} 8$ or 2964 that detect $A \beta$ independently of the modification state. In contrast, non-modified $\mathrm{A} \beta$ was almost exclusively detected as monomers. However, levels of monomeric non-modified $A \beta$ were also increased in RIPA extracts of APP/PS1 $\triangle E$ E-TREM2 ${ }^{\mathrm{T} 66 \mathrm{M}} \mathrm{KI}$ as compared to that of APP/PS1 1 E9-TREM2 WT mouse brains. In the SDS fractions that were obtained subsequently after extraction with RIPA buffer, and could also contain intracellular $A \beta$, levels of pSer8-A $\beta$ migrating in the monomeric band were similar between TREM2 WT and TREM2 $2^{\mathrm{T} 66 \mathrm{M}}$ brains. Notably, levels of oligomeric pSer8-A $\beta$ were elevated in TREM $2^{\text {T66M }}$ brains, indicating higher levels of pSer8-A $\beta$ containing oligomers upon loss of TREM2 function. As observed for the RIPA extracts, $n m A \beta$ was also not detected as oligomers in the SDS fraction. Levels of monomeric $n \mathrm{~mA} \beta$ were decreased in the SDS fraction of TREM2 $2^{\mathrm{T} 66 \mathrm{M}}$ mice as compared to that of TREM2 WT mice (Fig. 6i-l). Increased levels of oligomeric $A \beta$ in brains of TREM $2^{\mathrm{T} 66 \mathrm{M}}$ mice were confirmed with antibodies 4G8 and 2964 in both, RIPA and SDS extracts (Fig. $6 \mathrm{~m}-\mathrm{p}$ ). Together these data indicate that TREM2 could limit the accumulation of oligomeric $\mathrm{A} \beta$ assemblies which contain Ser8-A $\beta$. These oligomers might further aggregate to form $A \beta$ deposits consistent with the increased plaque deposition observed in brains of mice with TREM2 deletion or expression of the dysfunctional TREM2 $2^{\mathrm{T} 66 \mathrm{M}}$ variant. Notably, increased deposition of pSer8-A $\beta$ and $n m A \beta$ was not only observed in form of extracellular plaques, but also in brain vessels of APP/PS1L166P-TREM2 $2^{-/-}$mice as compared to APP/PS1L166P-TREM2 ${ }^{+/+}$mice (Additional file 1: Figure $\mathrm{S} 7 \mathrm{e}$ ). This vascular deposition of $\mathrm{A} \beta$ resembles cerebral amyloid angiopathy (CAA) observed in different APP transgenic mouse models, and very commonly in human AD brains [11, 37, 65].

\section{TREM2 variants are associated with quantitative} and qualitative differences in the deposition of distinct $A \beta$ species in human brains

To assess the effect of rare disease associated TREM2 variants in human brain tissue, $\mathrm{AD}$ cases with 


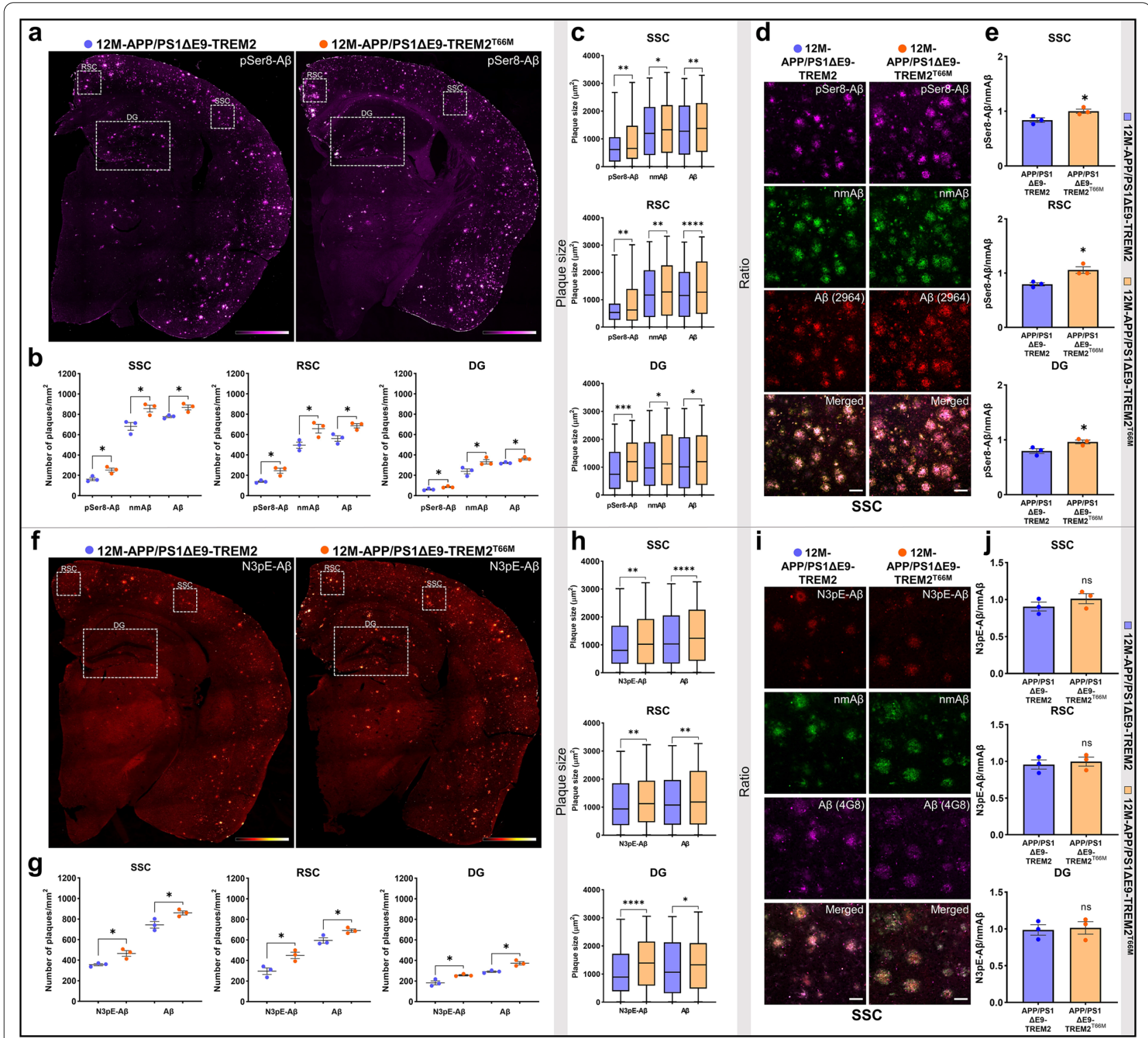

Fig. 4 TREM $2^{\text {T66M }}$ causes increased deposition of $p S e r 8-A \beta$ and N3PE-A $\beta$ in APP/PS1 transgenic mouse brains. a Representative $p S e r 8-A \beta$ stained female $12 \mathrm{M}$ old-APP/PS1 $\triangle$ E9-TREM2 and APP/PS1 $\triangle$ E9-TREM2 ${ }^{\mathrm{T} 66 \mathrm{M}}$ mouse brain sections (color scale bar $=35 \mathrm{~mm}$, represents min/max pixel intensities, 10x). b Dot plots representing number of plaques $/ \mathrm{mm}^{2}$, c Box and whiskers plots showing sizes of plaques ( $\left.\mu \mathrm{m}^{2}\right)$ stained with N3pE-A 3 , $\mathrm{nmA} \beta$, and A $\beta$ (2964) antibodies in the SSC, RSC, and DG of female $12 \mathrm{M}$ APP/PS1 $\triangle E$ E-TREM2 ${ }^{\text {T66M }}$ and APP/PS1 $\triangle E 9-T R E M 2$ mice. $\mathbf{d}$ Representative images showing deposition of pSer8-A $\beta, n m A \beta$, and $A \beta$ (2964) in SSC of female 12 M-APP/PS1 $\triangle E$ E-TREM2 ${ }^{\text {T66M }}$ and APP/PS1 $\triangle E$ E9-TREM2 mice (scale bar $=50 \mu \mathrm{m}, 40 x \mathrm{~W})$. e Ratio of $p S e r 8 / \mathrm{nmA} \beta$ in SSC $\left(t(3.953)=2.863,{ }^{*} p=0.0464\right)$, RSC $\left(t(2.915)=3.94,{ }^{*} p=0.0307\right)$, and DG $\left(t(3.743)=3.018,{ }^{*} p=0.0427\right)$ of female $12 \mathrm{M}$-APP/PS1 $\triangle E$ E-TREM2 ${ }^{\mathrm{T} 66 \mathrm{M}}$ compared with APP/PS1 $\triangle E 9-T R E M 2$ mice. $\mathbf{f}$ Representative N3pE-A $\beta$ stained female $12 \mathrm{M}$-APP/PS1 $\triangle$ E9-TREM2 and APP/PS1 $\triangle$ E9-TREM2 ${ }^{\text {T66M }}$ mouse brain sections (color scale bar $=35 \mathrm{~mm}$, represents min/max pixel intensities, 10x). g Dot plots representing number of plaques $/ \mathrm{mm}^{2}, \mathbf{h}$ Box and whiskers plots representing size of plaques $\left(\mu \mathrm{m}^{2}\right)$ stained with N3pE-A 3 and A $(4 G 8)$ antibodies in the SSC, RSC, and DG of the female 12 M-APP/PS1 $\triangle E$ E-TREM2 ${ }^{\text {T66M }}$ and APP/PS1 $\triangle E$ E-TREM2 mice. i Representative images showing deposition of N3PE-A, nmA , and AB (4G8) in SSC of female $12 \mathrm{M}$-APP/PS1 $\triangle E$ E-TREM2 ${ }^{\text {T66M }}$ and APP/PS1 $\triangle$ E9-TREM2 mice (scale

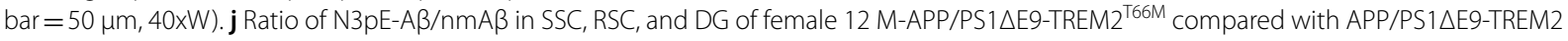
mice. Each dot represents average value of number of plaques or ratio/animal. The box and whiskers plots represent min/max values of distribution of plaque size with the median (shown by the line dividing the box) and the dot plots represent mean \pm SEM ( $n=3$ animals, color- blue (APP) PS1 $\triangle$ E9-TREM2) and orange (APP/PS1 $\triangle$ E9-TREM2 ${ }^{\text {T66M }}$ ), unpaired t-test with Welch's correction for analysis of the number and ratio while MannWhitney test for plaque size, ${ }^{\text {ns }} p>0.05,{ }^{*} p<0.05,{ }^{* *} p<0.01,{ }^{* * *} p<0.001$ or ${ }^{* * * *} p<0.0001$ ) 


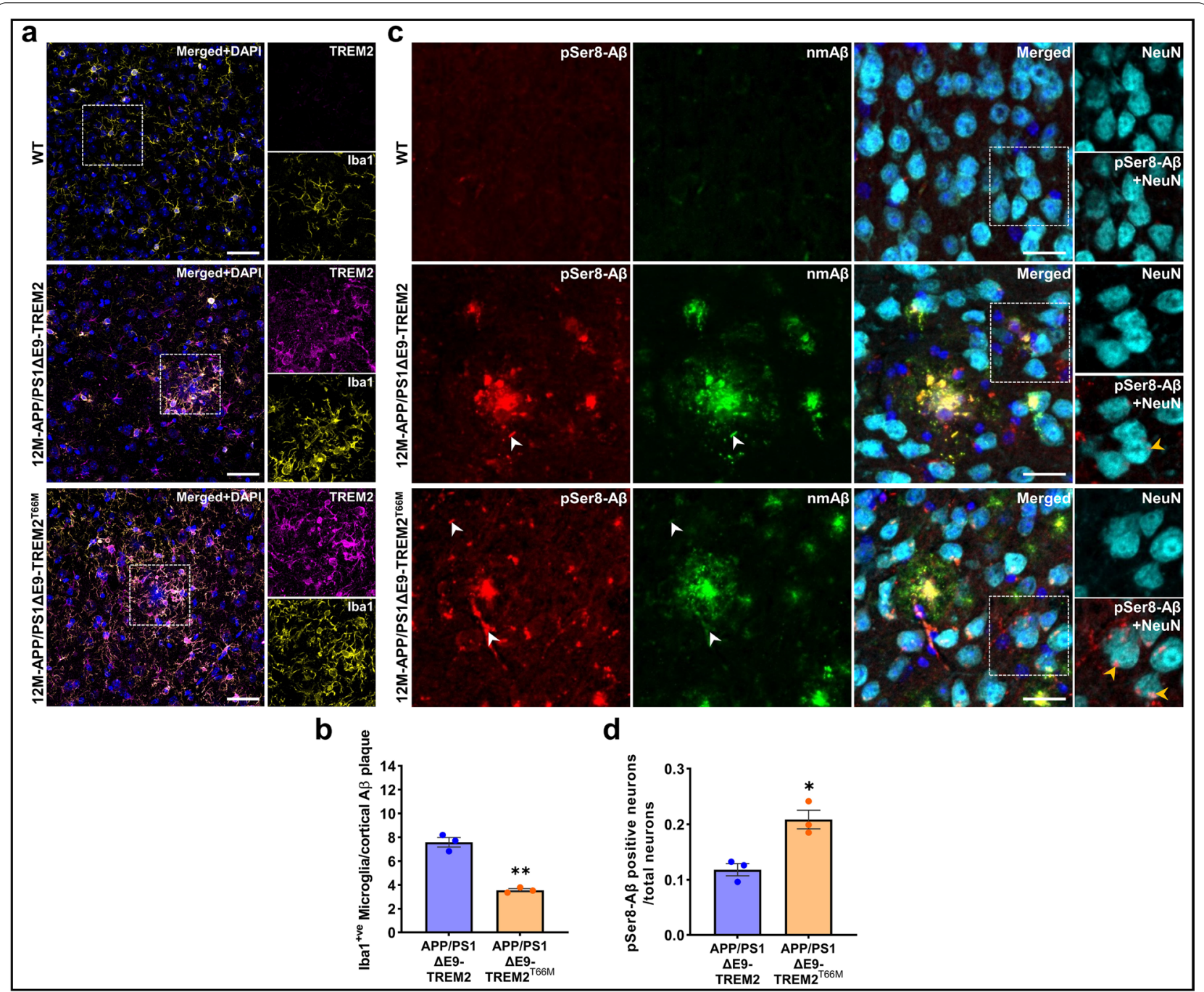

Fig. 5 TREM2 ${ }^{\text {T66M }}$ causes increased A $\beta$ in the APP/PS1 transgenic mouse brains. a Representative IF images of TREM2 along with microglial marker, Iba1 in female $12 \mathrm{M}$ old- APP/PS1 $\triangle$ E9 and APP/PS1 $\triangle$ E9-TREM2 ${ }^{\text {T66M }}$ mice. Dotted white boxes indicate the area shown at higher magnification (Scale $\mathrm{bar}=50 \mu \mathrm{m}, 20 \mathrm{x})$. b Quantification showing decreased plaque associated Iba $1^{+\mathrm{ve}}$ microglia surrounding cortical plaques in female $12 \mathrm{M}$-APP/ PS1 $\triangle$ E9-TREM2 ${ }^{\text {T66M }}$ as compared to APP/PS1 $\triangle$ E9-TREM2 mice $\left(t(2.392)=9.566,{ }^{* *} p=0.0058\right)$. Each dot represents the mean value of microglia count surrounding 30 cortical plaques/animal. c Representative IF images of pSer8-A $\beta$ and nmA localized in extracellular plaques, vessels (white

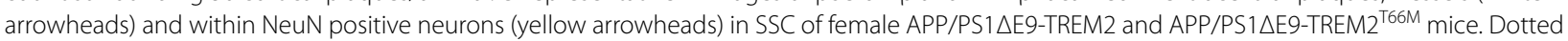
white boxes indicate the area shown at higher magnification (Scale bar $=50 \mu \mathrm{m}, 40 \mathrm{xW}$ ). $\mathbf{d}$ Quantification of intraneuronal pSer8-A $\mathrm{B}$ normalized to total number of neurons/ROI showed significantly increased intraneuronal pSer8-A $\beta$ deposits in the SSC of female 12 M-APP/PS1 $\triangle$ E9-TREM2 ${ }^{\text {T66M }}$ as compared to APP/PS1 $\triangle$ E9-TREM2 mice $\left(t(3.466)=4.459,{ }^{*} p<0.0154\right)$. All data represent mean \pm SEM $(n=3$ animals, color- blue (APP/ PS1 $\triangle E$ E-TREM2) and orange (APP/PS1 $\triangle$ E9-TREM2 ${ }^{T 66 \mathrm{M}}$ ), unpaired t-test with Welch's correction)

TREM2 $2^{\mathrm{R} 62 \mathrm{H} / \mathrm{R} 62 \mathrm{C}}$ variants and the clinical diagnosis for dementia were compared to cases with the TREM2 common variant $(\mathrm{CV})$ also diagnosed with dementia. All cases fulfilled the criteria for neuropathological diagnosis of AD (Table 2). Sequential temporal neocortical sections were stained separately with the phosphorylation-state specific antibodies 7H3D6 (nmA $\beta), 1 \mathrm{E} 4 \mathrm{E} 11$ (pSer8-A $\beta)$, and with $4 \mathrm{G} 8$ that detects $A \beta$ independently of the phosphorylation state. In addition to extracellular plaques, all cases showed $\mathrm{A} \beta$ depositions in the wall of cerebral blood vessels, and inside of neurons (Fig. 7a, Additional file 1: Figure S8a).

TREM2 $2^{\mathrm{R} 62 \mathrm{H} / \mathrm{R} 62 \mathrm{C}}$ variant cases had increased number and size of $4 \mathrm{G} 8$ positive plaques resulting in a higher plaque load (\% area) as compared to cases with the TREM2 common variant. Further, we also observed a higher number of smaller extracellular deposits stained with 4G8 antibody in TREM2 CV cases (Fig. 7a-d, 


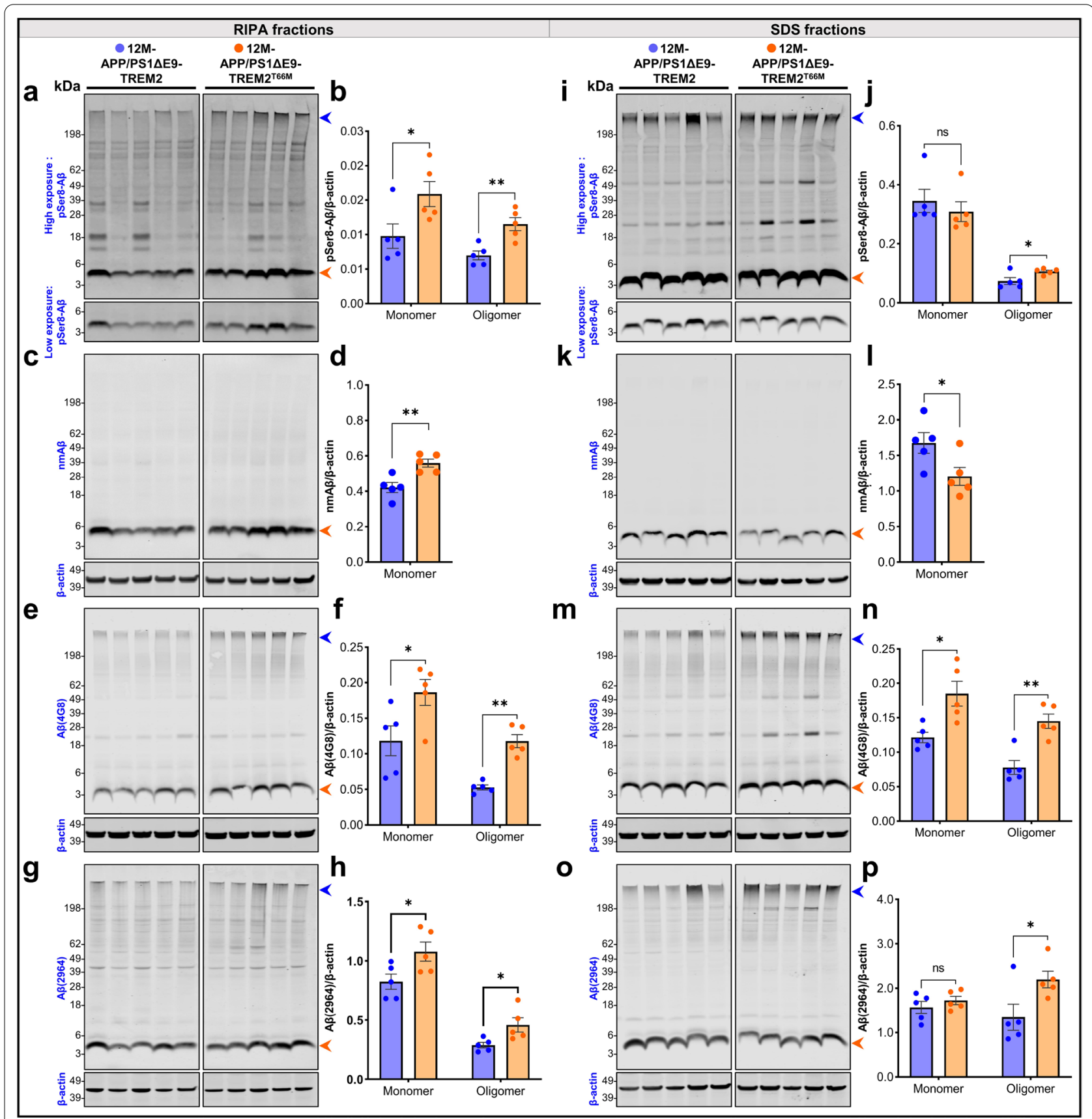

Fig. $\mathbf{6}$ Increased pSer8-A $\beta$ in brain extracts of APP/PS1 $\triangle$ E9-TREM2 ${ }^{T 66 \mathrm{M}}$ transgenic mouse brains. $\mathbf{a}-\mathbf{h}$ Immunoblots and quantification showing levels of monomeric and oligomeric A $\beta$ variants in RIPA extracts of brains of female $12 \mathrm{M}$ old-APP/PS1 $\triangle E$ E-TREM2 ${ }^{\text {T66M }}$ as compared to APP/ PS1 $\triangle E 9-T R E M 2$ mice; pSer8-Aß immunostained with antibody 1E4E11, (monomer: $t(7.993)=2.391,{ }^{*} p=0.0438 ;$ oligomer: $t(7.074)=3.925$,

$\left.{ }^{* *} p=0.0056\right), \mathrm{nmA} \beta$ detected with antibody $7 \mathrm{H} 3 \mathrm{D} 6$ (monomer: $\left.t(7.608)=3.849,{ }^{* *} p=0.0054\right), \mathrm{A} \beta$ immunostained with antibody $4 \mathrm{G} 8$ (monomer: $t(7.847)=2.454,{ }^{*} p=0.0402$; oligomer: $t(5.134)=6.604,{ }^{* *} p=0.0011$ ) or antibody 2964 (monomer: $t(7.607)=2.46,{ }^{*} p=0.0408$; oligomer: $t(5.181)=2.63,{ }^{*} p=0.045$ ) antibodies. $\mathbf{i}-\mathbf{p}$ Immunoblots and quantification showing levels of monomeric and oligomeric A $\beta$ variants in SDS extracts of brains of female $12 \mathrm{M}$-APP/PS1 $\triangle$ E9-TREM2 ${ }^{\text {T66M }}$ as compared to APP/PS1 $\triangle$ E9-TREM2 mice; pSer8-A 3 immunostained with antibody 1 E4E11, (monomer: $t(7.81)=0.708,{ }^{n s} p=0.4995$; oligomer: $\left.t(5.14)=2.62,{ }^{*} p=0.0458\right), n m A \beta$ detected with antibody $7 \mathrm{H} 3 \mathrm{D} 6$ ( monomer: $t(7.886)=2.449$, ${ }^{*} p=0.0404$ ), A $\beta$ immunostained with antibody $4 \mathrm{G} 8$ (monomer: $t(5.396)=3.255,{ }^{*} p=0.0202$; oligomer: $t(7.999)=4.642,{ }^{* *} p=0.0017$ ) or antibody 2964 (monomer: $t(7.153)=0.939,{ }^{n s} p=0.3784$; oligomer: $t(6.775)=2.434,{ }^{*} p=0.0463$ ) antibodies. Each dot represents ratio of A $\beta$ signal to $\beta$-actin per animal. All data represent mean \pm SEM ( $n=5$ animals, monomer: orange arrowheads and oligomer: blue arrowheads, color- blue (APP/PS1 $\triangle E 9-T R E M 2)$ and orange (APP/PS1 $\triangle$ E9-TREM2 ${ }^{T 66 \mathrm{M}}$ ), unpaired t-test with Welch's correction). Original uncropped immunoblots are provided in the Additional file 2: Source data 5 
Additional file 1: Figure S8b-c). Interestingly, only two of the six TREM2 $2^{\mathrm{R} 62 \mathrm{H} / \mathrm{R} 67 \mathrm{C}}$ cases showed very few extracellular nmA $\beta$ positive deposits, while five out of six cases with the TREM2 CV showed abundant deposition of $n m A \beta$ (detected by antibody 7H3D6) in extracellular plaques, indicating that deposition of N-terminally nonmodified $A \beta$ species is reduced in cases with disease associated TREM2 variants. In contrast, pSer8-A $\beta$ was present in extracellular plaques in TREM2 ${ }^{\mathrm{R} 62 \mathrm{H} / \mathrm{R} 62 \mathrm{C}}$ and TREM2 CV cases, and prominently detected in the core of plaques. The number of pSer8-A $\beta$ positive extracellular plaques and plaque load (\% area) was not significantly different between TREM2 $2^{\mathrm{R} 62 \mathrm{H} / \mathrm{R} 62 \mathrm{C}}$ and TREM2 CV cases (Fig. 7e-f). pSer8-A $\beta$ deposits stained with 1E4E11 were overall smaller as deposits stained with antibody $4 \mathrm{G8}$ that detects total $\mathrm{A} \beta$ with positively skewed plaque size distribution with both antibodies and in all cases (Fig. 7g, Additional file 1: Figure S8d-e). However, analysis of plaque size distribution revealed that the number and size of pSer8-A $\beta$ positive extracellular deposits were decreased in TREM2 $2^{\mathrm{R} 62 \mathrm{H} / \mathrm{R} 62 \mathrm{C}}$ cases as compared to TREM2 CV cases (Additional file 1: Figure S8d-e).

pSer8-A $\beta$ and $n m A \beta$ was also detected in vessels in TREM2 ${ }^{\mathrm{R} 62 \mathrm{H} / \mathrm{R} 62 \mathrm{C}}$ and TREM2 CV cases. However, further analyses on the regional and quantitative deposition of phosphorylated $A \beta$ species in different disease stages would be required to assess a potential effect of TREM2 genotypes on CAA in mouse and human brains (Additional file 1: Figures S7e, S8a; Fig. 7a).

We also observed intraneuronal deposition of $\mathrm{nmA} \beta$ and pSer8-A $\beta$ species. Interestingly, the number of neurons with $n m A \beta$ and pSer8-A $\beta$ positive intracellular deposits was significantly higher in TREM $2^{\mathrm{R} 62 \mathrm{H} / 62 \mathrm{C}}$ carriers as compared to TREM2 CV cases (Fig. $7 \mathrm{~h}-\mathrm{i}$ ).

\section{Discussion}

Here, we show that deletion of TREM2 or TREM2 disease associated variants lead to specific quantitative and qualitative changes of $A \beta$ deposits in brains of APP transgenic mice and human cases with the diagnosis of dementia, and that TREM2 not only modulates the composition of extracellular plaques, but also of intraneuronal deposits.

TREM2 plays a fundamental role in the regulation of microglial activity and the deposition of $A \beta$ in extracellular plaques $[28,29,31,68]$. $A \beta$ exists in multiple variants with different lengths and post-translational modifications which differ in their aggregation behavior, biostability, deposition and neurotoxic properties $[1,42]$. It was shown recently that phosphorylation of $A \beta$ modulates the direct interaction with TREM2 and the internalization by microglia [31]. Phosphorylation at Ser8 also decreases the degradation of $A \beta$ by the insulin degrading enzyme that can be secreted by microglia $[39,61]$.

To assess the role of TREM2 in the deposition of modified $A \beta$ species in-vivo, we analyzed $A \beta$ pathology in three different mouse models of $\mathrm{AD}$. Consistent with previous reports [28, 76], TREM2 deletion was associated with increased $A \beta$ deposition at younger (4-5 month) and older ages (12-15 month), and impaired microglial clustering around extracellular $A \beta$ plaques [31]. Importantly, the phosphorylated $A \beta$ species, pSer8-A $\beta$, selectively increased as compared to other $A \beta$ species in brains of 5xFAD and APP/PS1L166P transgenic mice upon deletion of TREM2. Increased accumulation of phosphorylated $A \beta$ species was also observed in brains of knockin (KI) mice with the TREM2 ${ }^{\mathrm{T} 66 \mathrm{M}}$ mutation that causes FTD-like syndrome and NHD in humans. In this regard,

\footnotetext{
(See figure on next page.)

Fig. 7 Differential deposition of phosphorylated A $\beta$ species in human brains with the common and rare variants of TREM2. a Temporal neocortex of human $A D$ patients with the indicated TREM2 variants (see Table 2) stained to detect total $A \beta$ (with $4 G 8$ ), $n m A \beta$, and pSer8-A 3 on consecutive sections. Immunostaining clearly indicated decreased deposition of $\mathrm{N}$-terminally non-modified A $\beta$ species in the TREM 2 variants. pSer8-A $\beta$ stained the plaques along with vascular as well as intracellular deposits. (Scale bar $=200 \mu \mathrm{m}, 20 \mathrm{x}$, the magnified dotted 4 red boxes within ROI and the small square boxes of $120 \times 120 \mu \mathrm{m}$ on the right-side (for plaques and vessels) represents deposition characteristics on consecutive sections except the square box of $45 \times 45 \mu \mathrm{m}$ for the neuronal deposits). b-c Quantification of the number of plaques $\left(t(6.997)=2.378,{ }^{*} p=0.0490\right)$ and percent plaque load $\left(t(7.786)=2.412,{ }^{*} p=0.0432\right)$ stained with $4 \mathrm{G} 8$ antibody in the analyzed ROls of TREM2 risk allele carriers (Plaque area cutoff $=10 \mu m^{2}$, $n=6$ cases each for TREM2 variants and CV, unpaired t-test with Welch's correction). $\mathbf{d}$ Box and whiskers plot showing a significant increase in the plaque size of TREM2 variants compared to CV cases ( $n=68,631$ (CV) and $n=88,835$ (TREM2 variants), ${ }^{* * *} p<0.0001$, Mann-Whitney test. Additional data are provided in Additional file 1: Figure S8b-c. e, f Quantification of the numbers of plaques $\left(t(6.96)=0.3754,{ }^{n s} p=0.7185\right)$ and the percent plaque load $\left(t(4.366)=0.5145,{ }^{n s} p=0.6319\right)$ stained with $p S e r 8-A \beta$ antibody in the analyzed ROls of TREM2 risk allele carriers (Plaque area cutoff $=30 \mu \mathrm{m}^{2}, \mathrm{n}=5$ cases for TREM2 variants and $\mathrm{n}=6$ cases for $\mathrm{CV}$, unpaired t-test with Welch's correction). Case\#3, with highest fixation time, was omitted for the plaque count and size quantification as it was difficult to identify extracellular plaques stained with 1E4E11 (pSer8-A $\beta$ ) antibody. g Box and whiskers plot showing a significant decrease in the plaque size of TREM2 variants compared to CV cases $(n=17,456(C V)$ and 13,291 (TREM2 variants), ${ }^{* * * *} p<0.0001$, Mann-Whitney test. Additional data are provided in Additional file 1: Figure S8d-e. There was a significant increase of intracellular deposits of $\mathbf{h} \mathrm{nmA} \beta\left(t(9.138)=2.429,{ }^{*} p=0.0377\right)$ and $\mathbf{i} p S e r 8-\mathrm{A} \beta\left(t(9.389)=2.251,{ }^{*} p=0.0497\right)$ in the analyzed cortical ROls of TREM2 variant as compared to CV cases ( $n=6$ cases each for TREM2 variants and CV, unpaired t-test with Welch's correction). No data or numerical value was excluded unless otherwise stated. Each colored dot with respective gender symbol represents single case. Except for bot and whiskers plot, all data represent mean \pm SEM
} 


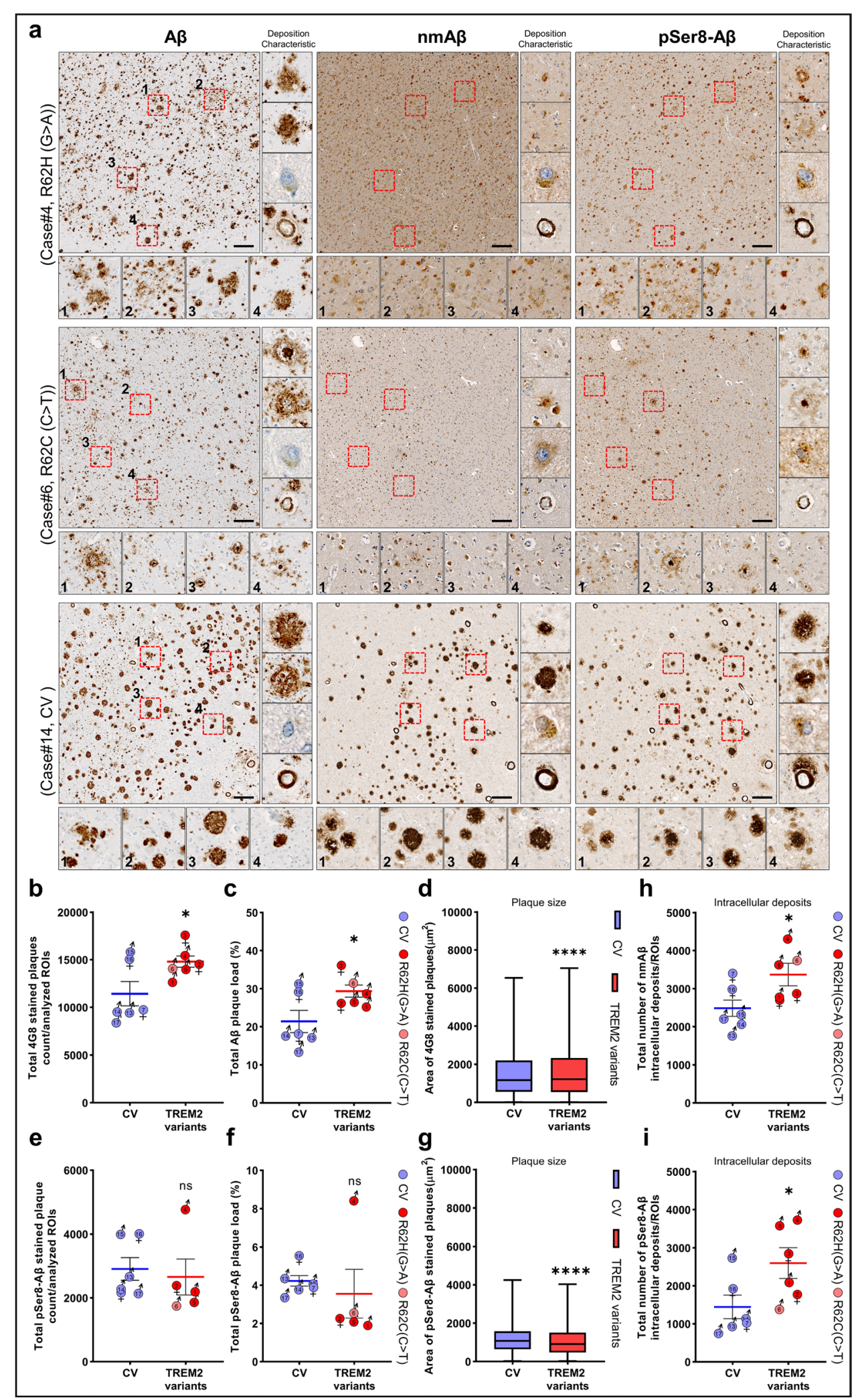

Fig. 7 (See legend on previous page.) 
it is interesting to note that NHD cases could show AD characteristic neuropathological lesions, including senile plaques and neurofibrillary tangles [4]. Consistent with previous findings $[31,36,40,41]$, pSer8- $A \beta$ is prominently detected in the core of extracellular plaques and intraneuronally. The deposition of pSer8-A $\beta$ in both lesions was increased in brains of $12 \mathrm{M}$ old TREM2 $2^{-/-}$ as compared with TREM2 $2^{+/+}$in $5 \times$ FAD as well as APP/ PS1L166P transgenic mice. Very similar alterations in the deposition of the different $A \beta$ species were also observed in TREM $2{ }^{\mathrm{T} 66 \mathrm{M}} \mathrm{KI}$ mice as compared to mice expressing functional TREM2, indicating that disease associated loss of function mutations also modulate the differential deposition of distinct $A \beta$ variants.

Biochemical analysis of brain extracts revealed that TREM2 deficiency or the expression of the NHD associated T66M in APP transgenic mice increased the levels of pSer8-A $\beta$ in form of oligomeric assemblies. $\mathrm{A} \beta$ oligomers exert neurotoxicity, and oligomer levels correlate with neuronal dysfunction in $\mathrm{AD}[3,21$, $50,56,57,62,80]$. A $\beta$ oligomers also seed fibrillization and promote the deposition in form of extracellular plaques [6,10, 20,32]. In addition, oligomers can be internalized by neurons resulting in $A \beta$ accumulation within neurons $[2,9,13,56,60]$. Since TREM2 has been shown to selectively bind oligomeric assemblies of $\mathrm{A} \beta$ and promote microglial uptake [31, 44, 72, 82], the loss of TREM2 function could result in decreased clearance of oligomers and thereby lead to increased uptake by neurons, and deposition in extracellular plaques and the vasculature. Indeed, altered plaque development and CAA related pathology has recently been observed in mouse brain upon depletion of microglia [23, 59], showing that functional microglia are important to shape extracellular plaques and to restrict the deposition of $A \beta$ in the brain vasculature. We also detected pSer8-A $\beta$ and $n m A \beta$ in vessels of transgenic mouse brains, and it will be interesting the further investigate the role of TREM2 in the deposition and the potential pathophysiological implications of modified $A \beta$ species in the vasculature.

The analysis of human cases with rare TREM $2^{\mathrm{R} 62 \mathrm{H}}$ or TREM2 ${ }^{\mathrm{R} 62 \mathrm{C}}$ variants showed significantly increased accumulation of phosphorylated $A \beta$ species inside of neurons and alterations in plaque size, load and number, further indicating that impairment of TREM2 function mediates the formation and composition of $\mathrm{AD}$ characteristic lesions.

Thus, in addition to the previously described effects of TREM2 on plaque morphology, our data provide evidence for a critical role of TREM2 in restriction of intraneuronal $A \beta$ deposits that are highly correlated with clinical presentation and disease progression $[2,7,14,15$, $27,63,77]$. Further, we show here that TREM2 also modulates the composition of these lesions. This is interesting, because changes in the composition of extracellular plaques and $\mathrm{CAA}$, in particular the occurrence of phosphorylated $A \beta$, are associated with clinical manifestation and progression of $\mathrm{AD}[11,46,54,64]$.

Although TREM2 loss of function mutations could also contribute to neurodegeneration independently of $\mathrm{A} \beta$ by impairment of brain energy metabolism [33], synapse dynamics [26, 48], and formation of neurofibrillary tangles [45], a recent study suggests an important role of $\mathrm{A} \beta$ pathology in the TREM 2 dependent formation of tau pathology and brain atrophy [43]. Thus, the differential interaction of TREM2 with modified $A \beta$ species might not only be important for the deposition and composition of different $A \beta$ lesions, but also contribute to the development of tau pathology that together determine onset and progression of AD.

\section{Abbreviations}

AD: Alzheimer's disease; ADAM: A disintegrin and metalloproteinases; ApoE4 Apolipoprotein E4 allele; APP: Amyloid precursor protein; A $\beta$ : Amyloid- $\beta$; CAA : Cerebral amyloid angiopathy; CV: Common variant; DAB: 3,3'-Diaminobenzidine; DAPI: 4',6-Diamidino-2-phenylindole; DG: Dentate gyrus; EDTA: Ethylenediaminetetraacetic acid; EGTA: Ethylene glycol-bis( $\beta$-aminoethyl ether)$\mathrm{N}, \mathrm{N}, \mathrm{N}^{\prime}, \mathrm{N}^{\prime}$-tetraacetic acid; EtOH: Ethanol; FAD: Familial Alzheimer's disease; FTD: Frontotemporal dementia; GWAS: Genome-wide association studies; IF: Immunofluorescence; IHC: Immunohistochemistry; IntDen: Integrated density; KI: Knock-In; NaDOC: Sodium Deoxycholate; N3pE-Aß: N-terminal pyroglutamate-modified Amyloid- $\beta$; NaOH: Sodium hydroxide; NFTs: Neurofibrillary tangles; NHD: Nasu-Hakola disease; nmA $\beta$ : Non-modified Amyloid- $\beta$; PBS: Phosphate buffer saline; pSer8-A $\beta$ : Phosphorylation at serine 8 of Amyloid- $\beta$; RIPA: Radioimmunoprecipitation assay; ROI: Region of interest; RSC: Retrosplenial cortex; RT: Room temperature; SDS: Sodium dodecyl sulphate; PAGE: Polyacrylamide gel electrophoresis; SSC: Somatosensory cortex; STREM2: Soluble variants of Triggering receptor expressed on myeloid cells 2; TREM2: Triggering receptor expressed on myeloid cells 2; Tris: Tris(hydroxymethyl)aminomethane; TBS: Tris-buffered saline; WT: Wild type.

\section{Supplementary Information}

The online version contains supplementary material available at https://doi. org/10.1186/s40478-021-01263-x.

Additional file 1: Supplementary figures.

Additional file 2: Source data.

\section{Acknowledgements}

This work was supported by the Deutsche Forschungsgemeinschaft, Grant WA1477/6-6 (to JW), the EU Innovative Medicines Initiative 2 Joint Undertaking (IMI2 JU), Grant/Award Number: No 115976 (PHAGO). PJ thanks the BIGS neuroscience and the University of Bonn for their support. PJ also thanks Lorenz Haase, Research department fundamental physics, Max Planck Institute for Radio Astronomy, Bonn, for his critical suggestions on the analysis done in this study. Authors thank the Microscopy Core Facility of the Medical Faculty at the University of Bonn for providing support and instrumentation funded by the Deutsche Forschungsgemeinschaft, Project Number: 388169927. 


\section{Authors' contributions}

PJ and JW conceived the study. PJ performed most of the experiments and analyzed data. SK, FR, and ST contributed to biochemical and immunohistochemical experiments and interpretation. SP, CH, MC, NV, and MTH provided mouse brains. PJ, TA and JH selected and analyzed human brains. PJ and JW wrote the manuscript with help all co-authors. All of the authors read, edited and approved the final version of the manuscript.

\section{Funding}

Open Access funding enabled and organized by Projekt DEAL.

\section{Availability of data and materials}

The data that support the findings of this study is available from the corresponding author upon reasonable request.

\section{Declarations}

\section{Competing interests}

The authors declare no competing financial interests.

\section{Author details}

${ }^{1}$ Department of Neurology, University of Bonn, Venusberg-Campus 1, (Formerly Sigmund-Freud-Str. 25), 53127 Bonn, Germany. ${ }^{2}$ Department of Neurodegenerative Diseases and Gerontopsychiatry, University Hospital Bonn, Bonn, Germany. ${ }^{3}$ Neuroinflammation Unit, German Center for Neurodegenerative Diseases e. V. (DZNE), Bonn, Germany. ${ }^{4}$ Biomedical Center (BMC), Faculty of Medicine, Ludwig-Maximilians-Universität München, Munich, Germany. ${ }^{5}$ Munich Cluster for Systems Neurology (SyNergy), Munich, Germany. ${ }^{6}$ Molecular Neurodegeneration Unit, German Center for Neurodegenerative Diseases e.V. (DZNE) Munich, Munich, Germany. ${ }^{7}$ Department of Pathology and Immunology, Washington University School of Medicine, St. Louis, USA. ${ }^{8}$ Center for Neuropathology and Prion Research, Ludwig-Maximilians-Universität München, Munich, Germany. ${ }^{9}$ Department of Psychiatry and Psychotherapy, Ludwig-Maximilians-Universität München, Munich, Germany.

Received: 13 September 2021 Accepted: 14 September 2021 Published online: 18 October 2021

\section{References}

1. Barykin EP, Mitkevich VA, Kozin SA, Makarov AA (2017) Amyloid beta modification: a key to the Sporadic Alzheimer's Disease? Front Genet 8:58. https://doi.org/10.3389/fgene.2017.00058

2. Bayer TA, Wirths $O$ (2010) Intracellular accumulation of amyloid-Beta-a predictor for synaptic dysfunction and neuron loss in Alzheimer's disease. Front Aging Neurosci 2:8. https://doi.org/10.3389/fnagi.2010.00008

3. Benilova I, Karran E, De Strooper B (2012) The toxic Abeta oligomer and Alzheimer's disease: an emperor in need of clothes. Nat Neurosci 15:349-357. https://doi.org/10.1038/nn.3028

4. Bird TD, Koerker RM, Leaird BJ, Vlcek BW, Thorning DR (1983) Lipomembranous polycystic osteodysplasia (brain, bone, and fat disease): a genetic cause of presenile dementia. Neurology 33:81-86. https://doi.org/10. 1212/wnl.33.1.81

5. Bis JC, Jian X, Kunkle BW, Chen Y, Hamilton-Nelson KL, Bush WS, Salerno WJ, Lancour D, Ma Y, Renton AE et al (2020) Whole exome sequencing study identifies novel rare and common Alzheimer's-Associated variants involved in immune response and transcriptional regulation. Mol Psychiatry 25:1859-1875. https://doi.org/10.1038/s41380-018-0112-7

6. Chen GF, Xu TH, Yan Y, Zhou YR, Jiang Y, Melcher K, Xu HE (2017) Amyloid beta: structure, biology and structure-based therapeutic development. Acta Pharmacol Sin 38:1205-1235. https://doi.org/10.1038/aps.2017.28

7. Condello C, Lemmin T, Stohr J, Nick M, Wu Y, Maxwell AM, Watts JC, Caro CD, Oehler A, Keene CD et al (2018) Structural heterogeneity and intersubject variability of Abeta in familial and sporadic Alzheimer's disease. Proc Natl Acad Sci USA 115:E782-E791. https://doi.org/10.1073/pnas. 1714966115

8. Condello C, Yuan P, Schain A, Grutzendler J (2015) Microglia constitute a barrier that prevents neurotoxic protofibrillar Abeta42 hotspots around plaques. Nat Commun 6:6176. https://doi.org/10.1038/ncomms7176
9. Friedrich RP, Tepper K, Ronicke R, Soom M, Westermann M, Reymann K, Kaether C, Fandrich M (2010) Mechanism of amyloid plaque formation suggests an intracellular basis of Abeta pathogenicity. Proc Natl Acad Sci USA 107:1942-1947. https://doi.org/10.1073/pnas.0904532106

10. Friesen M, Meyer-Luehmann M (2019) Abeta seeding as a tool to study cerebral amyloidosis and associated pathology. Front Mol Neurosci 12:233. https://doi.org/10.3389/fnmol.2019.00233

11. Gerth J, Kumar S, Rijal Upadhaya A, Ghebremedhin E, von Arnim CAF, Thal DR, Walter J (2018) Modified amyloid variants in pathological subgroups of beta-amyloidosis. Ann Clin Transl Neurol 5:815-831. https://doi.org/10. 1002/acn3.577

12. Glebov K, Wunderlich P, Karaca I, Walter J (2016) Functional involvement of gamma-secretase in signaling of the triggering receptor expressed on myeloid cells-2 (TREM2). J Neuroinflammation 13:17. https://doi.org/10. 1186/s12974-016-0479-9

13. Gouras GK, Almeida CG, Takahashi RH (2005) Intraneuronal Abeta accumulation and origin of plaques in Alzheimer's disease. Neurobiol Aging 26:1235-1244. https://doi.org/10.1016/j.neurobiolaging.2005.05.022

14. Gouras GK, Tampellini D, Takahashi RH, Capetillo-Zarate E (2010) Intraneuronal beta-amyloid accumulation and synapse pathology in Alzheimer's disease. Acta Neuropathol 119:523-541. https://doi.org/10.1007/ s00401-010-0679-9

15. Gouras GK, Tsai J, Naslund J, Vincent B, Edgar M, Checler F, Greenfield JP, Haroutunian V, Buxbaum JD, Xu H et al (2000) Intraneuronal Abeta42 accumulation in human brain. Am J Pathol 156:15-20. https://doi.org/10. 1016/s0002-9440(10)64700-1

16. Gratuze M, Leyns CEG, Holtzman DM (2018) New insights into the role of TREM2 in Alzheimer's disease. Mol Neurodegener 13:66. https://doi.org/ 10.1186/s13024-018-0298-9

17. Guerreiro R, Bilgic B, Guven G, Bras J, Rohrer J, Lohmann E, Hanagasi H, Gurvit H, Emre M (2013) Novel compound heterozygous mutation in TREM2 found in a Turkish frontotemporal dementia-like family. Neurobiol Aging 34(2890):e2891-2895. https://doi.org/10.1016/j.neurobiolaging. 2013.06.005

18. Guerreiro R, Wojtas A, Bras J, Carrasquillo M, Rogaeva E, Majounie E, Cruchaga C, Sassi C, Kauwe JS, Younkin S et al (2013) TREM2 variants in Alzheimer's disease. N Engl J Med 368:117-127. https://doi.org/10.1056/ NEJMoa1211851

19. Guerreiro RJ, Lohmann E, Bras JM, Gibbs JR, Rohrer JD, Gurunlian N, Dursun B, Bilgic B, Hanagasi H, Gurvit H et al (2013) Using exome sequencing to reveal mutations in TREM2 presenting as a frontotemporal dementialike syndrome without bone involvement. JAMA Neurol 70:78-84. https://doi.org/10.1001/jamaneurol.2013.579

20. Hardy J, Selkoe DJ (2002) The amyloid hypothesis of Alzheimer's disease: progress and problems on the road to therapeutics. Science 297:353356. https://doi.org/10.1126/science.1072994

21. He Y, Wei M, Wu Y, Qin H, Li W, Ma X, Cheng J, Ren J, Shen Y, Chen Z et al (2019) Amyloid beta oligomers suppress excitatory transmitter release via presynaptic depletion of phosphatidylinositol-4,5-bisphosphate. Nat Commun 10:1193. https://doi.org/10.1038/s41467-019-09114-z

22. Heneka MT, Kummer MP, Stutz A, Delekate A, Schwartz S, Vieira-Saecker A, Griep A, Axt D, Remus A, Tzeng TC et al (2013) NLRP3 is activated in Alzheimer's disease and contributes to pathology in APP/PS1 mice. Nature 493:674-678. https://doi.org/10.1038/nature11729

23. Huang Y, Happonen KE, Burrola PG, O'Connor C, Hah N, Huang L, Nimmerjahn A, Lemke G (2021) Microglia use TAM receptors to detect and engulf amyloid beta plaques. Nat Immunol. https://doi.org/10.1038/ s41590-021-00913-5

24. Hyman BT, Phelps CH, Beach TG, Bigio EH, Cairns NJ, Carrillo MC, Dickson DW, Duyckaerts C, Frosch MP, Masliah E et al (2012) National Institute on Aging-Alzheimer's Association guidelines for the neuropathologic assessment of Alzheimer's disease. Alzheimers Dement 8:1-13. https://doi.org/ 10.1016/j.jalz.2011.10.007

25. Ibach M, Mathews M, Linnartz-Gerlach B, Theil S, Kumar S, Feederle R, Brustle O, Neumann H, Walter J (2021) A reporter cell system for the triggering receptor expressed on myeloid cells 2 reveals differential effects of disease-associated variants on receptor signaling and activation by antibodies against the stalk region. Glia 69:1126-1139. https://doi.org/10. 1002/glia.23953

26. Jadhav VS, Lin PBC, Pennington T, Di Prisco GV, Jannu AJ, Xu G, Moutinho M, Zhang J, Atwood BK, Puntambekar SS et al (2020) Trem2 Y38C 
mutation and loss of Trem2 impairs neuronal synapses in adult mice. Mol Neurodegener 15:62. https://doi.org/10.1186/s13024-020-00409-0

27. Jawhar S, Trawicka A, Jenneckens C, Bayer TA, Wirths O (2012) Motor deficits, neuron loss, and reduced anxiety coinciding with axonal degeneration and intraneuronal Abeta aggregation in the 5XFAD mouse model of Alzheimer's disease. Neurobiol Aging 33(196):e129-140. https://doi.org/ 10.1016/j.neurobiolaging.2010.05.027

28. Jay TR, Miller CM, Cheng PJ, Graham LC, Bemiller S, Broihier ML, Xu G, Margevicius D, Karlo JC, Sousa GL et al (2015) TREM2 deficiency eliminates TREM $2^{+}$inflammatory macrophages and ameliorates pathology in Alzheimer's disease mouse models. J Exp Med 212:287-295. https://doi. org/10.1084/jem.20142322

29. Jiang T, Tan L, Zhu XC, Zhang QQ, Cao L, Tan MS, Gu LZ, Wang HF, Ding ZZ, Zhang YD et al (2014) Upregulation of TREM2 ameliorates neuropathology and rescues spatial cognitive impairment in a transgenic mouse model of Alzheimer's disease. Neuropsychopharmacology 39:2949-2962. https://doi.org/10.1038/npp.2014.164

30. Jonsson T, Stefansson H, Steinberg S, Jonsdottir I, Jonsson PV, Snaedal J, Bjornsson S, Huttenlocher J, Levey Al, Lah JJ et al (2013) Variant of TREM2 associated with the risk of Alzheimer's disease. N Engl J Med 368:107116. https://doi.org/10.1056/NEJMoa1211103

31. Joshi P, Riffel F, Satoh K, Enomoto M, Qamar S, Scheiblich H, Villacampa N, Kumar S, Theil S, Parhizkar S et al (2021) Differential interaction with TREM2 modulates microglial uptake of modified Abeta species. Glia. https://doi.org/10.1002/glia.24077

32. Katzmarski N, Ziegler-Waldkirch S, Scheffler N, Witt C, Abou-Ajram C, Nuscher B, Prinz M, Haass C, Meyer-Luehmann M (2020) Abeta oligomers trigger and accelerate Abeta seeding. Brain Pathol 30:36-45. https://doi. org/10.1111/bpa.12734

33. Kleinberger G, Brendel M, Mracsko E, Wefers B, Groeneweg L, Xiang X, Focke C, Deussing M, Suarez-Calvet M, Mazaheri F et al (2017) The FTDlike syndrome causing TREM2 T66M mutation impairs microglia function, brain perfusion, and glucose metabolism. EMBO J 36:1837-1853. https:// doi.org/10.15252/embj.201796516

34. Kleinberger G, Yamanishi Y, Suarez-Calvet M, Czirr E, Lohmann E, Cuyvers E, Struyfs H, Pettkus N, Wenninger-Weinzierl A, Mazaheri F et al (2014) TREM2 mutations implicated in neurodegeneration impair cell surface transport and phagocytosis. Sci Transl Med 6:243ra286. https://doi.org/ 10.1126/scitranslmed.3009093

35. Konishi H, Kiyama H (2018) Microglial TREM2/DAP12 signaling: a doubleedged sword in neural diseases. Front Cell Neurosci 12:206. https://doi. org/10.3389/fncel.2018.00206

36. Kumar S, Kapadia A, Theil S, Joshi P, Riffel F, Heneka MT, Walter J (2021) Novel phosphorylation-state specific antibodies reveal differential deposition of Ser26 phosphorylated A $\beta$ species in a mouse model of Alzheimer's disease. Front Mol Neurosci. https://doi.org/10.3389/fnmol. 2020.619639

37. Kumar S, Lemere CA, Walter J (2020) Phosphorylated Abeta peptides in human Down syndrome brain and different Alzheimer's-like mouse models. Acta Neuropathol Commun 8:118. https://doi.org/10.1186/ s40478-020-00959-w

38. Kumar S, Rezaei-Ghaleh N, Terwel D, Thal DR, Richard M, Hoch M, Mc Donald JM, Wullner U, Glebov K, Heneka MT et al (2011) Extracellular phosphorylation of the amyloid beta-peptide promotes formation of toxic aggregates during the pathogenesis of Alzheimer's disease. EMBO J 30:2255-2265. https://doi.org/10.1038/emboj.2011.138

39. Kumar S, Singh S, Hinze D, Josten M, Sahl HG, Siepmann M, Walter J (2012) Phosphorylation of amyloid-beta peptide at serine 8 attenuates its clearance via insulin-degrading and angiotensin-converting enzymes. J Biol Chem 287:8641-8651. https://doi.org/10.1074/jbc.M111.279133

40. Kumar S, Wirths O, Stuber K, Wunderlich P, Koch P, Theil S, Rezaei-Ghaleh N, Zweckstetter M, Bayer TA, Brustle O et al (2016) Phosphorylation of the amyloid beta-peptide at Ser26 stabilizes oligomeric assembly and increases neurotoxicity. Acta Neuropathol 131:525-537. https://doi.org/ 10.1007/s00401-016-1546-0

41. Kumar S, Wirths O, Theil S, Gerth J, Bayer TA, Walter J (2013) Early intraneuronal accumulation and increased aggregation of phosphorylated Abeta in a mouse model of Alzheimer's disease. Acta Neuropathol 125:699-709. https://doi.org/10.1007/s00401-013-1107-8

42. Kummer MP, Heneka MT (2014) Truncated and modified amyloid-beta species. Alzheimer's Res Therapy 6:28. https://doi.org/10.1186/alzrt258
43. Lee SH, Meilandt WJ, Xie L, Gandham VD, Ngu H, Barck KH, Rezzonico MG, Imperio J, Lalehzadeh G, Huntley MA et al (2021) Trem2 restrains the enhancement of tau accumulation and neurodegeneration by betaamyloid pathology. Neuron 109:1283-1301 e1286. https://doi.org/10. 1016/j.neuron.2021.02.010

44. Lessard CB, Malnik SL, Zhou Y, Ladd TB, Cruz PE, Ran Y, Mahan TE, Chakrabaty P, Holtzman DM, Ulrich JD et al (2018) High-affinity interactions and signal transduction between Abeta oligomers and TREM2. EMBO Mol Med. https://doi.org/10.15252/emmm.201809027

45. Leyns CEG, Ulrich JD, Finn MB, Stewart FR, Koscal LJ, Remolina Serrano J, Robinson GO, Anderson E, Colonna M, Holtzman DM (2017) TREM2 deficiency attenuates neuroinflammation and protects against neurodegeneration in a mouse model of tauopathy. Proc Natl Acad Sci USA 114:11524-11529. https://doi.org/10.1073/pnas.1710311114

46. Libard S, Walter J, Alafuzoff I (2021) In vivo characterization of biochemical variants of amyloid-beta in subjects with idiopathic normal pressure hydrocephalus and Alzheimer's disease neuropathological change. J Alzheimers Dis 80:1003-1012. https://doi.org/10.3233/JAD-201469

47. Linnartz-Gerlach B, Bodea LG, Klaus C, Ginolhac A, Halder R, Sinkkonen L, Walter J, Colonna M, Neumann H (2019) TREM2 triggers microglial density and age-related neuronal loss. Glia 67:539-550. https://doi.org/ 10.1002/glia.23563

48. Mazaheri F, Snaidero N, Kleinberger G, Madore C, Daria A, Werner G, Krasemann S, Capell A, Trumbach D, Wurst W et al (2017) TREM2 deficiency impairs chemotaxis and microglial responses to neuronal injury. EMBO Rep 18:1186-1198. https://doi.org/10.15252/embr.201743922

49. Paloneva J, Autti T, Raininko R, Partanen J, Salonen O, Puranen M, Hakola P. Haltia M (2001) CNS manifestations of Nasu-Hakola disease: a frontal dementia with bone cysts. Neurology 56:1552-1558. https://doi.org/10 1212/wnl.56.11.1552

50. Palop JJ, Mucke L (2010) Amyloid-beta-induced neuronal dysfunction in Alzheimer's disease: from synapses toward neural networks. Nat Neurosci 13:812-818. https://doi.org/10.1038/nn.2583

51. Parhizkar S, Arzberger T, Brendel M, Kleinberger G, Deussing M, Focke C, Nuscher B, Xiong M, Ghasemigharagoz A, Katzmarski N et al (2019) Loss of TREM 2 function increases amyloid seeding but reduces plaqueassociated ApoE. Nat Neurosci 22:191-204. https://doi.org/10.1038/ s41593-018-0296-9

52. Portelius E, Bogdanovic N, Gustavsson MK, Volkmann I, Brinkmalm G, Zetterberg H, Winblad B, Blennow K (2010) Mass spectrometric characterization of brain amyloid beta isoform signatures in familial and sporadic Alzheimer's disease. Acta Neuropathol 120:185-193. https://doi.org/10. 1007/s00401-010-0690-1

53. Rezaei-Ghaleh N, Amininasab M, Kumar S, Walter J, Zweckstetter M (2016) Phosphorylation modifies the molecular stability of beta-amyloid deposits. Nat Commun 7:11359. https://doi.org/10.1038/ncomms11359

54. Rijal Upadhaya A, Kosterin I, Kumar S, von Arnim CA, Yamaguchi H, Fandrich M, Walter J, Thal DR (2014) Biochemical stages of amyloid-beta peptide aggregation and accumulation in the human brain and their association with symptomatic and pathologically preclinical Alzheimer's disease. Brain 137:887-903. https://doi.org/10.1093/brain/awt362

55. Saido TC, Iwatsubo T, Mann DM, Shimada H, Ihara Y, Kawashima S (1995) Dominant and differential deposition of distinct beta-amyloid peptide species, A beta N3(pE), in senile plaques. Neuron 14:457-466. https://doi. org/10.1016/0896-6273(95)90301-1

56. Schutzmann MP, Hasecke F, Bachmann S, Zielinski M, Hansch S, Schroder GF, Zempel H, Hoyer W (2021) Endo-lysosomal Abeta concentration and $\mathrm{pH}$ trigger formation of Abeta oligomers that potently induce Tau missorting. Nat Commun 12:4634. https://doi.org/10.1038/ s41467-021-24900-4

57. Sengupta U, Nilson AN, Kayed R (2016) The role of amyloid-beta oligomers in toxicity, propagation, and immunotherapy. EBioMedicine 6:42-49. https://doi.org/10.1016/j.ebiom.2016.03.035

58. Serrano-Pozo A, Mielke ML, Muzitansky A, Gomez-Isla T, Growdon JH, Bacskai BJ, Betensky RA, Frosch MP, Hyman BT (2012) Stable size distribution of amyloid plaques over the course of Alzheimer disease. J Neuropathol Exp Neurol 71:694-701. https://doi.org/10.1097/NEN.0b013e31825e77de

59. Spangenberg E, Severson PL, Hohsfield LA, Crapser J, Zhang J, Burton EA, Zhang Y, Spevak W, Lin J, Phan NY et al (2019) Sustained microglial depletion with CSF1R inhibitor impairs parenchymal plaque development in 
an Alzheimer's disease model. Nat Commun 10:3758. https://doi.org/10. 1038/s41467-019-11674-z

60. Takahashi RH, Almeida CG, Kearney PF, Yu F, Lin MT, Milner TA, Gouras GK (2004) Oligomerization of Alzheimer's beta-amyloid within processes and synapses of cultured neurons and brain. J Neurosci 24:3592-3599. https://doi.org/10.1523/JNEUROSCI.5167-03.2004

61. Tamboli IY, Barth E, Christian L, Siepmann M, Kumar S, Singh S, Tolksdorf K, Heneka MT, Lutjohann D, Wunderlich P et al (2010) Statins promote the degradation of extracellular amyloid \{beta\}-peptide by microglia via stimulation of exosome-associated insulin-degrading enzyme (IDE) secretion. J Biol Chem 285:37405-37414. https://doi.org/10.1074/jbc. M110.149468

62. Tanokashira D, Mamada N, Yamamoto F, Taniguchi K, Tamaoka A, Lakshmana MK, Araki W (2017) The neurotoxicity of amyloid beta-protein oligomers is reversible in a primary neuron model. Mol Brain 10:4. https:// doi.org/10.1186/s13041-016-0284-5

63. Thal DR, Griffin WS, Braak H (2008) Parenchymal and vascular Abetadeposition and its effects on the degeneration of neurons and cognition in Alzheimer's disease. J Cell Mol Med 12:1848-1862. https://doi.org/10. 1111/j.1582-4934.2008.00411.x

64. Thal DR, Ronisz A, Tousseyn T, Rijal Upadhaya A, Balakrishnan K, Vandenberghe R, Vandenbulcke M, von Arnim CAF, Otto M, Beach TG et al (2019) Different aspects of Alzheimer's disease-related amyloid beta-peptide pathology and their relationship to amyloid positron emission tomography imaging and dementia. Acta Neuropathol Commun 7:178. https:// doi.org/10.1186/s40478-019-0837-9

65. Thal DR, Walter J, Saido TC, Fandrich M (2015) Neuropathology and biochemistry of Abeta and its aggregates in Alzheimer's disease. Acta Neuropathol 129:167-182. https://doi.org/10.1007/s00401-014-1375-y

66. Turnbull IR, Gilfillan S, Cella M, Aoshi T, Miller M, Piccio L, Hernandez M, Colonna M (2006) Cutting edge: TREM-2 attenuates macrophage activation. J Immunol 177:3520-3524. https://doi.org/10.4049/jimmunol.177.6. 3520

67. Ulland TK, Song WM, Huang SC, Ulrich JD, Sergushichev A, Beatty WL, Loboda AA, Zhou Y, Cairns NJ, Kambal A et al (2017) TREM2 maintains microglial metabolic fitness in Alzheimer's disease. Cell 170:649-663 e613. https://doi.org/10.1016/j.cell.2017.07.023

68. Ulrich JD, Finn MB, Wang Y, Shen A, Mahan TE, Jiang H, Stewart FR, Piccio L, Colonna M, Holtzman DM (2014) Altered microglial response to Abeta plaques in APPPS1-21 mice heterozygous for TREM2. Mol Neurodegener 9:20. https://doi.org/10.1186/1750-1326-9-20

69. Ulrich JD, Holtzman DM (2016) TREM2 function in Alzheimer's disease and neurodegeneration. ACS Chem Neurosci 7:420-427. https://doi.org/ 10.1021/acschemneuro.5b00313

70. Venegas C, Kumar S, Franklin BS, Dierkes T, Brinkschulte R, Tejera D, VieiraSaecker A, Schwartz S, Santarelli F, Kummer MP et al (2017) Microgliaderived ASC specks cross-seed amyloid-beta in Alzheimer's disease. Nature 552:355-361. https://doi.org/10.1038/nature25158

71. Verheijen J, Sleegers K (2018) Understanding Alzheimer disease at the interface between genetics and transcriptomics. Trends Genet 34:434-447. https://doi.org/10.1016/j.tig.2018.02.007

72. Vilalta A, Zhou Y, Sevalle J, Griffin JK, Satoh K, Allendorf DH, De S, Puigdellivol M, Bruzas A, Burguillos MA et al (2021) Wild-type sTREM2 blocks Abeta aggregation and neurotoxicity, but the Alzheimer's R47H mutant increases Abeta aggregation. J Biol Chem 296:100631. https://doi.org/10. 1016/j.jbc.2021.100631

73. Wahle T, Thal DR, Sastre M, Rentmeister A, Bogdanovic N, Famulok M, Heneka MT, Walter J (2006) GGA1 is expressed in the human brain and affects the generation of amyloid beta-peptide. J Neurosci 26:1283812846. https://doi.org/10.1523/JNEUROSCI.1982-06.2006

74. Walter J (2016) The triggering receptor expressed on myeloid cells 2: a molecular link of neuroinflammation and neurodegenerative diseases. J Biol Chem 291:4334-4341. https://doi.org/10.1074/jbc.R115.704981

75. Wang Y, Cella M, Mallinson K, Ulrich JD, Young KL, Robinette ML, Gilfillan S, Krishnan GM, Sudhakar S, Zinselmeyer BH et al (2015) TREM2 lipid sensing sustains the microglial response in an Alzheimer's disease model. Cell 160:1061-1071. https://doi.org/10.1016/..cell.2015.01.049

76. Wang Y, Ulland TK, Ulrich JD, Song W, Tzaferis JA, Hole JT, Yuan P, Mahan TE, Shi Y, Gilfillan S et al (2016) TREM2-mediated early microglial response limits diffusion and toxicity of amyloid plaques. J Exp Med 213:667-675. https://doi.org/10.1084/jem.20151948

77. Welikovitch LA, Do Carmo S, Magloczky Z, Malcolm JC, Loke J, Klein WL, Freund T, Cuello AC (2020) Early intraneuronal amyloid triggers neuronderived inflammatory signaling in APP transgenic rats and human brain. Proc Natl Acad Sci USA 117:6844-6854. https://doi.org/10.1073/pnas. 1914593117

78. Wunderlich P, Glebov K, Kemmerling N, Tien NT, Neumann H, Walter $\mathrm{J}$ (2013) Sequential proteolytic processing of the triggering receptor expressed on myeloid cells-2 (TREM2) protein by ectodomain shedding and gamma-secretase-dependent intramembranous cleavage. J Biol Chem 288:33027-33036. https://doi.org/10.1074/jbc.M1 13.517540

79. Xiang X, Piers TM, Wefers B, Zhu K, Mallach A, Brunner B, Kleinberger G, Song W, Colonna M, Herms J et al (2018) The Trem2 R47H Alzheimer's risk variant impairs splicing and reduces Trem $2 \mathrm{mRNA}$ and protein in mice but not in humans. Mol Neurodegener 13:49. https://doi.org/10.1186/ s13024-018-0280-6

80. Yoo SJ, Son G, Bae J, Kim SY, Yoo YK, Park D, Baek SY, Chang KA, Suh YH, Lee YB et al (2020) Longitudinal profiling of oligomeric Abeta in human nasal discharge reflecting cognitive decline in probable Alzheimer's disease. Sci Rep 10:11234. https://doi.org/10.1038/s41598-020-68148-2

81. Yuan P, Condello C, Keene CD, Wang Y, Bird TD, Paul SM, Luo W, Colonna M, Baddeley D, Grutzendler J (2016) TREM2 haplodeficiency in mice and humans impairs the microglia barrier function leading to decreased amyloid compaction and severe axonal dystrophy. Neuron 90:724-739. https://doi.org/10.1016/j.neuron.2016.05.003

82. Zhao Y, Wu X, Li X, Jiang LL, Gui X, Liu Y, Sun Y, Zhu B, Pina-Crespo JC, Zhang M et al (2018) TREM2 is a receptor for beta-Amyloid that mediates microglial function. Neuron 97:1023-1031 e1027. https://doi.org/10. 1016/j.neuron.2018.01.031

83. Zhong L, Chen XF, Wang T, Wang Z, Liao C, Wang Z, Huang R, Wang D, Li $X$, Wu L et al (2017) Soluble TREM2 induces inflammatory responses and enhances microglial survival. J Exp Med 214:597-607. https://doi.org/10. 1084/jem.20160844

\section{Publisher's Note}

Springer Nature remains neutral with regard to jurisdictional claims in published maps and institutional affiliations.

\footnotetext{
Ready to submit your research? Choose BMC and benefit from:

- fast, convenient online submission

- thorough peer review by experienced researchers in your field

- rapid publication on acceptance

- support for research data, including large and complex data types

- gold Open Access which fosters wider collaboration and increased citations

- maximum visibility for your research: over 100M website views per year
}

At BMC, research is always in progress.

Learn more biomedcentral.com/submissions 